\title{
Design of a wireless power transfer system for assisted living applications
}

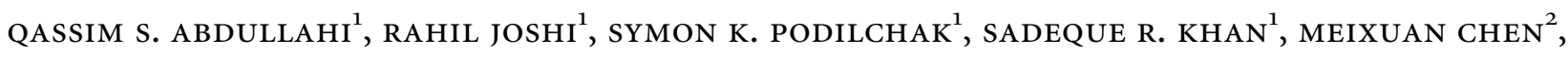 \\ JEAN ROONEY ${ }^{3}$, JOHN ROONEY ${ }^{3}$, DANMEI SUN ${ }^{2}$, MARC P.Y. DESMULLIEZ ${ }^{1}$, APOSTOLOS GEORGIADIS ${ }^{1}$ \\ AND DIMITRIS ANAGNOSTOU ${ }^{1}$
}

\begin{abstract}
Advances in material science and semiconductor technology have enabled a variety of inventions to be implemented in electronic systems and devices used in the medical, telecommunications, and consumer electronics sectors. In this paper, a wireless charging system is described as a wearable body heater that uses a chair as a transmitter (Tx). This system incorporates the widely accepted $Q i$ wireless charging standard. Alignment conditions of a linear three-element coil arrangement and $a 3 \times 3$ coil matrix array are investigated using voltage induced in a coil as a performance indicator. The efficiency obtained is demonstrated to be up to $80 \%$ for a voltage of over 6.5 Volts and a power transfer of over 5 Watts. Our results and proposed approach can be useful for many applications. This is because the wireless charging system described herein can help design seating areas for the elderly and disabled, commercial systems, consumer electronics, medical devices, electronic textiles (e-textiles), and other electronic systems and devices.
\end{abstract}

Keywords: Coil, Near field, Array, Wireless power transfer, Assisted living applications

Received 15 November 2018; Revised 30 January 2019; Accepted 7 February 2019

\section{INTRODUCTION}

Smart clothing is a new trend in wearable technology aimed at improving human life and satisfaction. Such clothing is made using combinations of micro-electronics embedded in fabrics to create functional and fashionable solutions that meet people's everyday needs. An area of interest is assisted living (AL), which takes into consideration the delicate needs of elderly individuals. In many countries, such as the USA and European Union (EU) countries, modern medicine has increased the longevity of people's lives. However, such countries are also experiencing a decreasing birth-rate that is leading to a disproportionate amount of people aged 65 and above when compared to the younger working population [1]. With current trends, it is estimated that, in the next 30 years, the elderly (i.e. individuals aged 65 or older) will outnumber their younger counterparts in the $\mathrm{EU}$, for example, two to one [2]. This phenomenon will create a higher demand for AL solutions that can be used to provide longterm care to the aging population [3].

The primary objective of AL technologies is to improve lives by providing security, comfort, and independence [4]. These technologies can be applied to different environments,

${ }^{1}$ School of Engineering and Physical Sciences, Heriot-Watt University, Edinburgh, UK

${ }^{2}$ School of Textiles and Design, Heriot-Watt University, Edinburgh, UK

${ }^{3}$ Feel the Warmth, Edinburgh, UK

Corresponding author:

Q. Abdullahi Email: qsa1@hw.ac.uk

S.K. Podilchak Email: skp@ieee.org

A. Georgiadis Email: apostolos.georgiadis@ieee.org from homes and offices to outdoor public facilities [5-16]. However, devices used in an $\mathrm{AL}$ system requires a continuous source of power which can be provided by supportive batteries (e.g. lithium-ion batteries) [17]. However, currently available batteries cannot always meet the demands of the devices that make up an AL system [18]. That is, prolonged use of an AL system's devices eventually requires battery recharging and replacement, which can be a tedious, expensive, and complicated task for the elderly and other individuals [15]. For example, replacing batteries in biomedical implants is expensive and a complex procedure. Research into energy harvesting [19-21], wireless charging [22-26], battery and power management $[27-29]$ has been conducted for AL systems to improve the functionality and efficiency of device batteries.

Wireless charging offers a great solution to the problems with batteries as described above. For example, this way of charging batteries can be more convenient to a user of an AL system than wired charging and some early examples have been demonstrated [18], [30], and [31]. To address safety concerns of the technology, regulations and standards of implementing wireless power transfer (WPT) for charging should also be considered [32-38]. Currently, two main commercial WPT standards exist: (i) the Qi standard created by the wireless power consortium (WPC) and (ii) the A4WP standard the air fuel alliance (AFA). Both standards enable wireless charging techniques that use magnetic induction to transfer power from a transmitter $(T x)$ to a corresponding receiver $(R x)$ within a target device. WPC's $Q i$ and AFA's A4WP standards are discussed extensively in [39-41]. The two standards meet the international and regional regulations on safety and electromagnetic interference set up by government and health agencies [32]. Safety 
considerations are made by selecting a non-radiative WPT system design described in [42-50]. More specifically, the research presented in this paper is directed to exploring the design of a WPT system for wirelessly charging a wearable heating belt.

The challenges faced by these wirelessly charged devices include: (i) electromagnetic safety levels that lead to regulatory restrictions, which require a low power source with higher transmission efficiency [47]; (ii) limited range of operation, which leads to positioning issues of the transmitter and receiver [48]; and (iii) problems with integrating the transmitter and receiver in a seamless way to the user's everyday environment $[49,50]$.

Works in [18], [30], [51-54] have also demonstrated high power transmission efficiency (PTE) using different approaches. For example, using small biomedical implant coils a PTE of $58 \%$ was achieved in [18]. Metamaterials have also been used to increase PTE in medium power applications [30]. In [52] and [53], a transmitter coil array was used to improve PTE to up to 85 and $50 \%$, respectively.

Positioning issues have also been researched and overcome using different techniques in some works in [52], [55], [56], and [57]. In [52], primary coils were embedded into a desk surface which significantly improved the charging area. Further, [55] used a sequence of switchable couples of coils to adopt a transmitting link side that retains its coupling coefficient for a continuously moving receiver. In [56], a similar concept to [52] was adopted using magnetically coupled resonant wireless power, while [57] used a bowl-shaped transmitter coil for free positioning.

In our proposed design as reported in this paper, which is based on the widely accepted $Q i$ wireless charging standard, the transmitter of the WPT system is integrated within a backrest of a chair, while the WPT system's receiver is integrated in the user's belt together with a novel far-infrared heating element (see Figs 1(a) and $1(\mathrm{~b})$ ). The belt can be charged

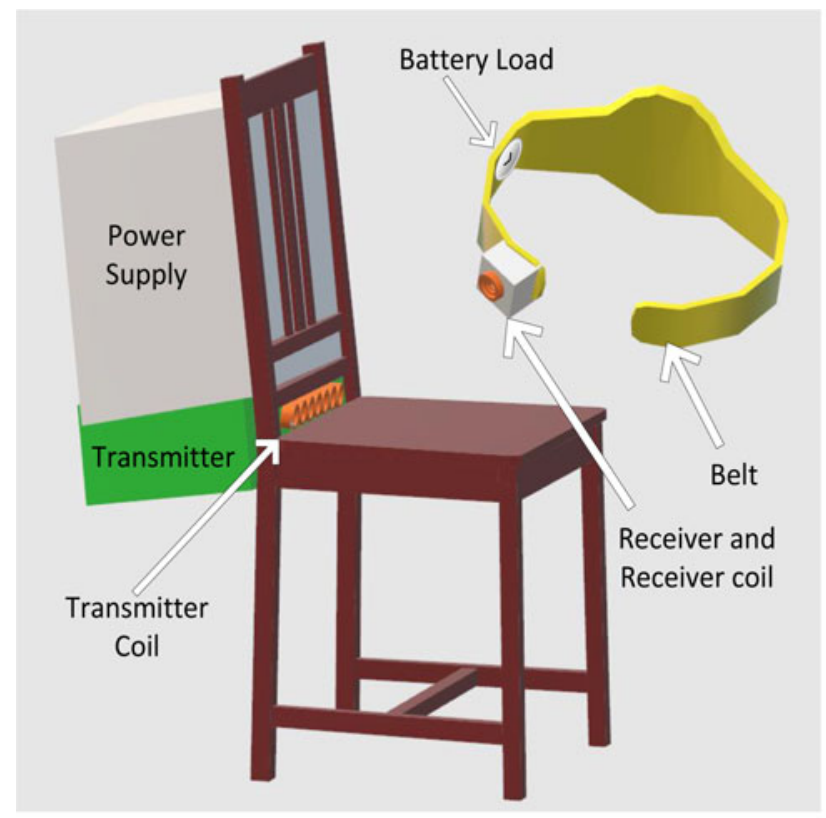

(a) while its user is seated in the chair. This paper also investigates and examines alignment and power transfer conditions of the charging area on a chair's backrest, considering different coil arrangements and arrays. The WPT system proposed can also be used in multiple charging scenarios, including AL environments. In this way, the proposed WPT charging and heating system can be seamlessly integrated into the user's life with ease and comfort.

\section{WIRELESS SYSTEM DESIGN}

The major factors that affect the performance of the WPT system described herein are: (i) distance and misalignment between the transmitter and receiver; and (ii) power transfer between the transmitter and receiver. Both are attributable to inductive power transfer, which is specified by the $Q i$ standard [39]. Table 1 shows the initial design constraints of the system.

When the separation distance of the coils for the system is smaller than $1 / 10^{\text {th }}$ of the wavelength of magnetic field, an Equivalent Lumped Parameter Circuit Model of the system can be made as further described in [58].

The first constraint requires that the receiver to be near the transmitter of the WPT system. More specifically, and as shown in Fig. 1(b), the belt to be charged (which includes

Table 1. System specifications.

\begin{tabular}{ll}
\hline Parameters & Value \\
\hline Pout (W) & 5 \\
Vout (V) & $5-7$ \\
Vin (V) & 12 \\
Transfer distance & $<3 \mathrm{~cm}$ \\
Efficiency & $70-80 \%$ \\
\hline
\end{tabular}

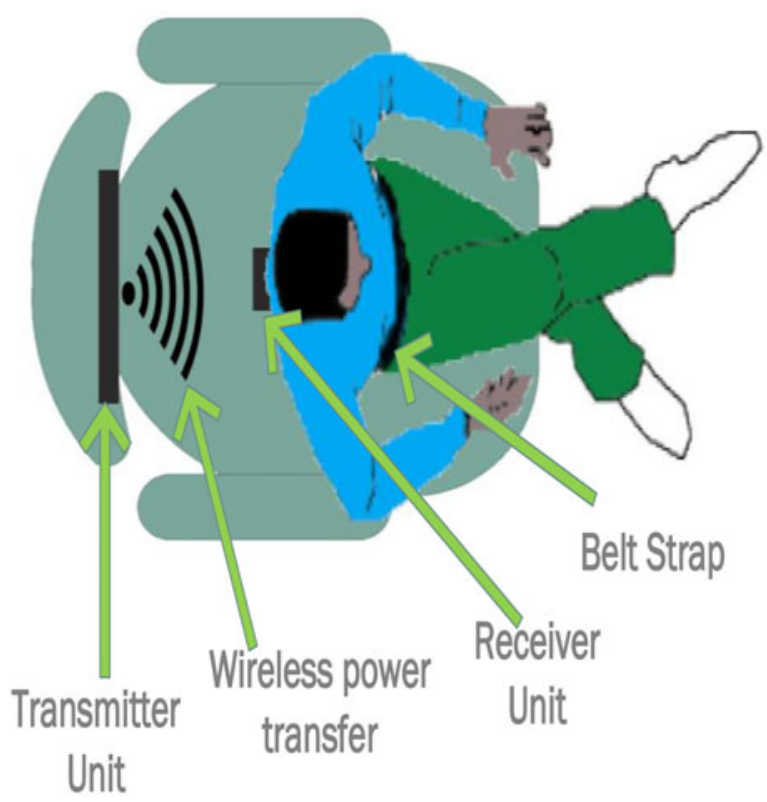

(b)

Fig. 1. (a) Illustration of the wireless power system to power a belt and integration into a chair. (b) Setup showing the working concept of the WPT system when the user is sitting on the chair. The actual wearable belt can be seen in Fig. 2 . 
the receiver) must be close to the chair's backrest (which includes the transmitter). Furthermore, the second constraint requires power transfer in our WPT system to occur at any sitting position. The proposed WPT system overcomes the constraints described above by using an array of coils to be embedded in the backrest of the chair (previously shown in Fig. 1) and as similarly used in [52] and [56]. Thus our proposed design as described in Fig. 2 can increase the coverage area for WPT.

The main design constraints of the coil size of the system include the physical dimensions of the belt (for the receiver) and load (li-ion battery pack). The battery has a nominal input voltage of $7 \mathrm{~V}$ and an input power of $5 \mathrm{~W}$ as specified in [59].

Our design process is shown in Fig. 3 and physical dimensions of the coils were used as initial input parameters to calculate the required self-inductance of the coils and mutual inductance by the theory reported [6o], which was then optimized based on the power transfer efficiency (PTE). The receiver coil had restrictions due to the belt size while there were no size constraints for the transmitter, other than it needed to fit within a chair.

$$
\eta=\frac{1}{1+\left[A \frac{R_{1}}{R_{L}}\right]+\left[R_{2} \frac{R_{L}}{\left(w L_{2}\right)^{2}}\right]} .
$$

The circuit was then tuned to obtain the resonant capacitors for the primary and secondary coils by following [61]. These parameters were then used in the simulation environment for further optimization and where the Keysight software Advanced Design System (ADS) was employed.

\section{A) Transmitter parameters}

The transmitting unit is based on the WPC1.1 Q $i$ specification with a $5 \mathrm{~W}$ power level [62]. A WPC A29-type coil was used and characterized with parameters as in [63]. The transmitter coil is fabricated from litz wire with nylon spinning having
180 strands of no. 40 AWG (0.08 mm diameter). The measured inductance and quality factor of the transmitter coil were $10 \mu \mathrm{H}$ and 90, respectively. A ferrite sheet was placed underneath the coil to shield the electronics in the base of the charger [64].

\section{B) Receiver parameters}

The design constraints for the individual receiving coil $(32 \times$ $48 \mathrm{~mm}^{2}$ ) was more due to the limited dimensions of the textile belt. During the initial design phase, efforts were made to ensure that the employed receiver coil was able to provide a suitable mutual inductance [65] and thus provide sufficient coupling; i.e. the coil had an inductance of $15 \mu \mathrm{H}$ and a quality factor of 60 (Fig. 4 illustrates the design process in terms of size, load resistance and coupling distance). Table 2 shows the performance data of the transmitter and receiver modules.

\section{WIRELESSPOWER DESIGN}

The wireless system transmits power from a transmitter embedded in a chair then a belt containing the receiver unit receives and harvests the power. The harvested power is used to provide a regulated supply voltage suitable for charging the lithium-ion battery. The connection between the battery and the receiver has been implemented on a breadboard. Voltmeters and ammeters were connected to allow power consumption to be measured, as shown in Fig. 4 .

\section{SYSTEM MDDELING AND SIMULATION}

Modeling the wireless power system (transmitter and receiver modules) through a simulation tool is an important part of the design before implementing the physical system. This kind of simulation-based approach can help to estimate and quantify expected outcomes of the real time experimentation. The

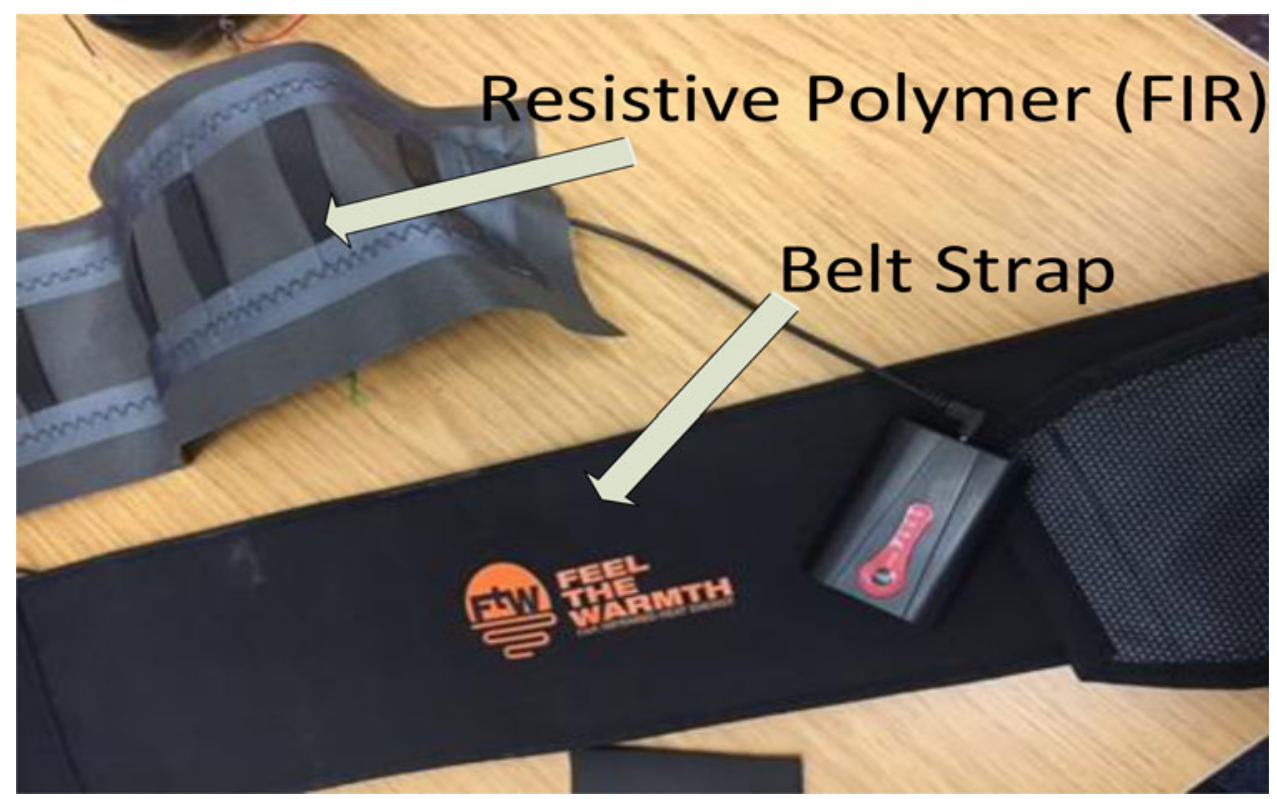

Fig. 2. Wearable belt with the charging element. 


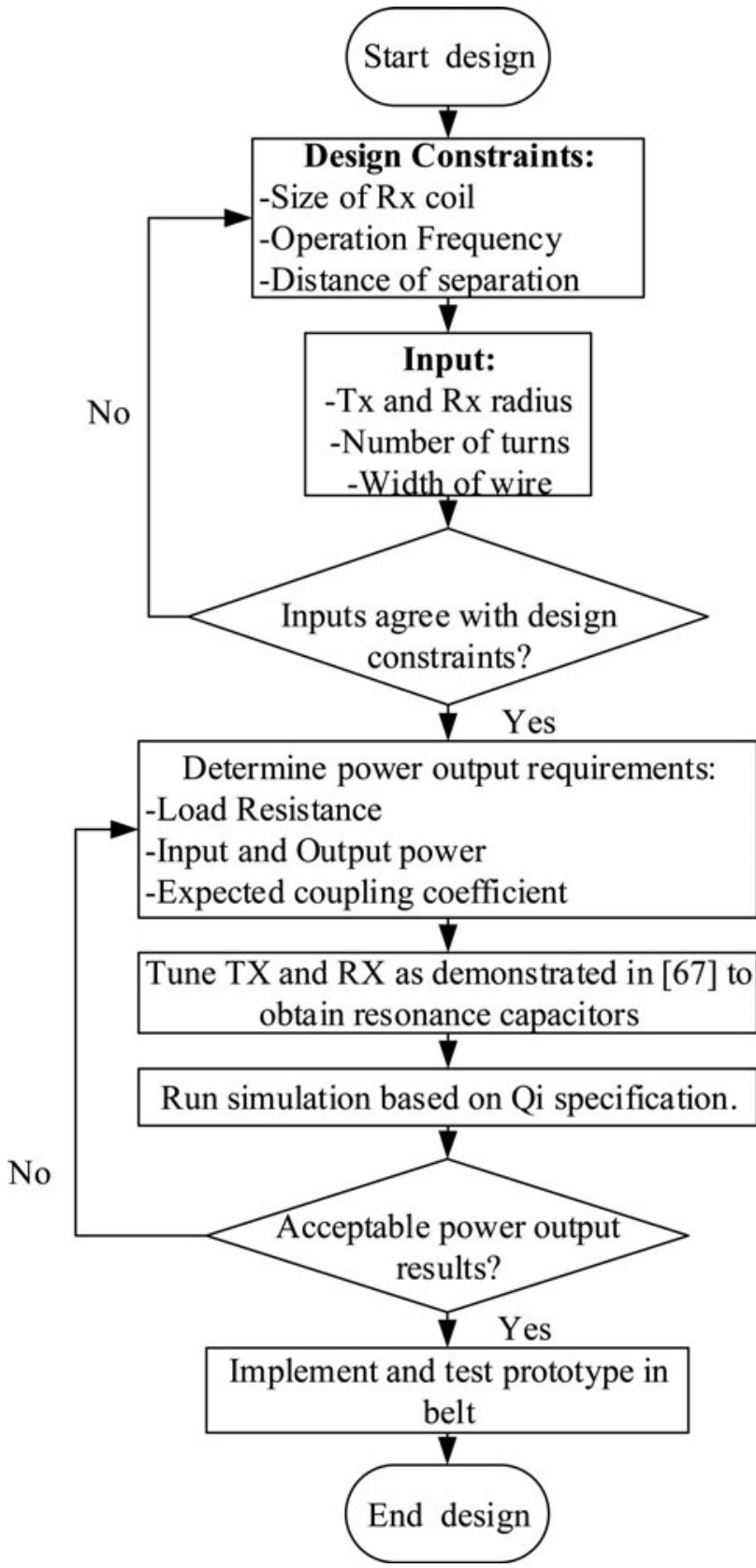

Fig. 3. Flowchart of the design methodology for the proposed WPT system.

simulation software Keysight ADS was used to obtain the power output at the receiver for any coupling condition using coil types of the chosen transmitter and receiver modules.

The transmitter and receiver modules operated using inductive coupling regulated by the $Q i$ standard which operates at frequencies between 100 and $200 \mathrm{kHz}$. The transmitter module is made up of an oscillator capable of producing the required resonant frequency. An amplifier then drives alternating current into the primary coil. The receiver converts the signal to DC through rectifying circuits [39].

The combination of the BQ500215EVM-648 wireless power transmitter and the $\mathrm{BQ} 51025 \mathrm{EVM}-649$ receiver shown in Fig. 8 are expected to give an output of $7 \mathrm{~V}$ at a maximum current of $1 \mathrm{~A}$.

\section{A) Coupling factor and coil modeling}

Coupling factor quantifies the strength of magnetic field generated by the transmitter coil and it varies between o and 1 . It must be noted that, when $k=1$ this represents perfect coupling. Coupling is also highly dependent on the distance between the coils as will be shown in the paper.

From [66] and [67] the inductance of the transmitter and receiver modules were obtained respectively to calculate the coupling coefficient, $k$, before calculating the mutual inductance between the coils, $M$. Also, the coupling factor can be measured from an existing system as a relative open loop voltage, $u$, it can be given as follows from (5a) in [61]:

$$
u=\frac{U_{2}}{U_{1}}=k \sqrt{\frac{L_{22}}{L_{11}}},
$$

where $U_{1}$ and $U_{2}$ are the voltages applied to coil, $L_{11}$ is the selfinductance of the transmitter coil, and $L_{22}$ is the self-inductance of the receiver coil. These parameters are also related to the general set of equations for coupled inductors as seen in [68]:

$$
\begin{aligned}
& \frac{U_{1}}{j \omega}=L_{11} I_{1}+M I_{2}=L_{11} I_{1}+\Phi_{12}, \\
& \frac{U_{2}}{j \omega}=M I_{1}+L_{22} I_{2}=\Phi_{21}+L_{22} I_{2} .
\end{aligned}
$$

Inserting equation (2) into equations (3) and (4) we get the following:

$$
\begin{aligned}
& \frac{U_{1}}{j \omega}=L_{11} I_{1}+\Phi_{12}, \\
& \frac{U_{2}}{j \omega}=\Phi_{21}+L_{22} I_{2} .
\end{aligned}
$$

These equations show that the voltage can be expressed in the form of flux density. This condition is possible when the transmitting and receiving coils are coupled strongly with each other, in other words, a very small distance is separating them [69]. The overall measured inductance is given by $L_{S}$ in [61], which is:

$$
L_{S}=L_{11}+L_{22}+(2 M) \text {. }
$$

\section{B) Resonant capacitors}

The receiver circuit has two resonant capacitors $C_{s}$, and a series resonant capacitor and $C_{s p}$. These capacitors along with the receiver coil make up a dual resonant circuit. The two capacitors are used to tune the receiver coil and by the Q $i$ standard, should be sized correctly based on the WPC specification [62], and where the receiver coil is then placed on the spacer, and $L_{r x}$ is measured with a stimulus of $1-\mathrm{V}$ RMS and $100 \mathrm{kHz}$. These capacitors can be further calculated using the $100 \mathrm{kHz}$ resonant frequency:

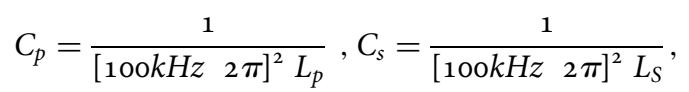




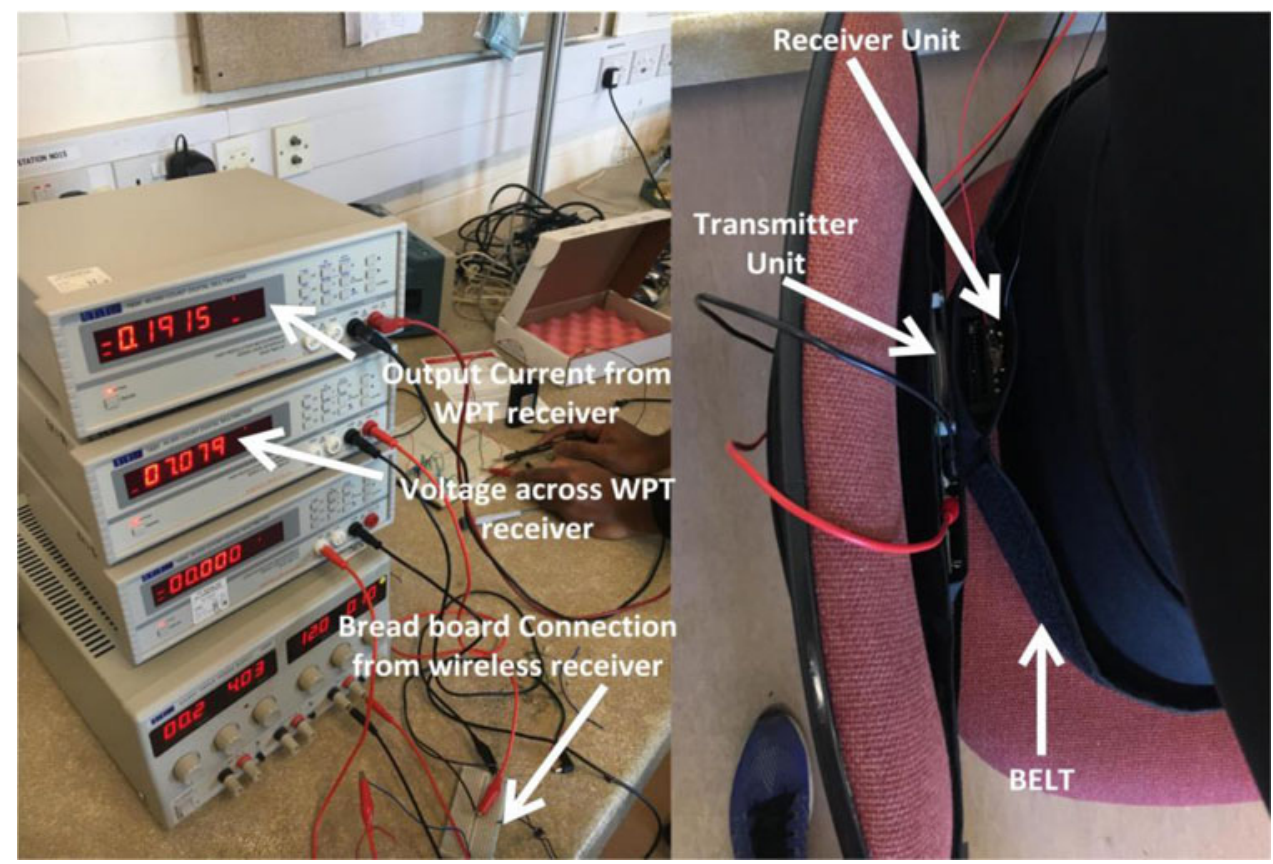

Fig. 4. Left side shows measurement equipment and setup. Right side shows the wireless power system operating in the belt and a chair.

and $C_{s p}$ is the secondary resonance considering $1 \mathrm{MHz}$ :

$$
C_{s p}=\frac{1}{\left[\begin{array}{ll}
1 M H z & 2 \pi
\end{array}\right]^{2}\left[L_{S}-\frac{1}{C_{s}}\right]} .
$$

The quality factor must also be $>77$ after tuning and is given by:

$$
Q=\frac{1 M H z \quad 2 \pi L_{S}}{R}
$$

where $R$ is the resistance of the coil. Table 3 below shows data calculated for the circuit modeling.

\section{C) PTE simulations}

Figure 5(a) shows the circuit schematic of the modeled wireless power system while Fig. 5(b) shows the ADS schematic of the system. This simulation model is expanded on and based on the reported findings from [70]. The source is an oscillator

Table 2. Relevant parameter for selected transmitter and receiver units.

\begin{tabular}{ll}
\hline Transmitter & BQ500215EVM-648 \\
\hline Power supply & AC $100 \sim 240 \mathrm{~V}(50 / 60 \mathrm{~Hz})$ \\
Nominal Vin & $11.5-12 \mathrm{~V}$ \\
Rated output & $7 \mathrm{~V}, 10 \mathrm{~W}$ \\
Estimated overall system efficiency & 80 \\
Operating frequency & $100-205 \mathrm{kHz}$ \\
\hline Receiver & $595-\mathrm{BQ} 51025 \mathrm{EVM}-649$ \\
\hline Max Vin & $20 \mathrm{~V}$ \\
Rated output & $4.5-10 \mathrm{~V}, 10 \mathrm{~W}$ \\
Estimated overall system efficiency & 80 \\
Operating frequency & $100-205 \mathrm{kHz}$ \\
\hline
\end{tabular}

which generates the $\mathrm{AC}$ signal at $100 \mathrm{kHz}$ that flows into the transmitter coil, $L_{p}$ generates an oscillating magnetic field, $C_{p}$ is the resonant capacitor calculated from equation (8) that generates a resonance for $L_{p}$ with a coil resistance of $R$ equation (10). Through the mutual induction tool from ADS, energy from the magnetic field induces $\mathrm{AC}$ current in the receiver coil, $L_{s}$.

At the receiver the conventional bridge diodes made of Schottky diodes, convert the signal to DC. $C_{s}$ is the series resonant capacitor calculated in equation (8) while $C_{s p}$ is the parallel resonant capacitor calculated in equation (9) for the receiver coil under test. This receiver model is based on the Qi specification in [63] for type A5.

Figure 6 shows the rectified voltage of a $15 \Omega$ load to be between 6.7 and $7 \mathrm{~V}$. The current is between $500 \mathrm{~mA}$ (0.5 A) and $460 \mathrm{~mA}(0.46 \mathrm{~A})$. The output power was tabulated for a load resistance ranging from 3 to $200 \Omega$.

The lithium ion battery used in our system has a high resistance at full charge. Also, to measure the impedance, a battery must be at least $50 \%$ charged in practice. A completely drained or nearly empty battery has a high internal resistance. As the battery reaches 50\% state-of-charge (SOC), the resistance drops and then increases again towards full charge [6o]. Table 4

Table 3. Data for simulation setup.

\begin{tabular}{lll}
\hline & Transmitter & \multicolumn{1}{c}{ Receiver } \\
\hline Self-Inductance $(\mu \mathrm{H})$ & 10 & 15 \\
Coil impedance $(\mathrm{Ohm})$ & 0.174 & 0.157 \\
Quality factor & 90 & 60 \\
Coupling factor & 0.59 & 0.59 \\
Primary resonant capacitor, $C_{p}(\mathrm{~F})$ & $1.0132 \times 10^{-7}$ & $\mathrm{~N} / \mathrm{A}$ \\
Series resonant capacitor, $C_{s}(\mathrm{~F})$ & N/A & $5.3052 \times 10^{-8}$ \\
Parallel resonant capacitor, $C_{s p}(\mathrm{~F})$ & N/A & $1.3438 \times 10^{-23}$ \\
Source voltage, $V_{o}(\mathrm{~V})$ & 5 & N/A \\
Load impedance, $Z_{L}(\Omega)$ & N/A & $3-200$ \\
\hline
\end{tabular}



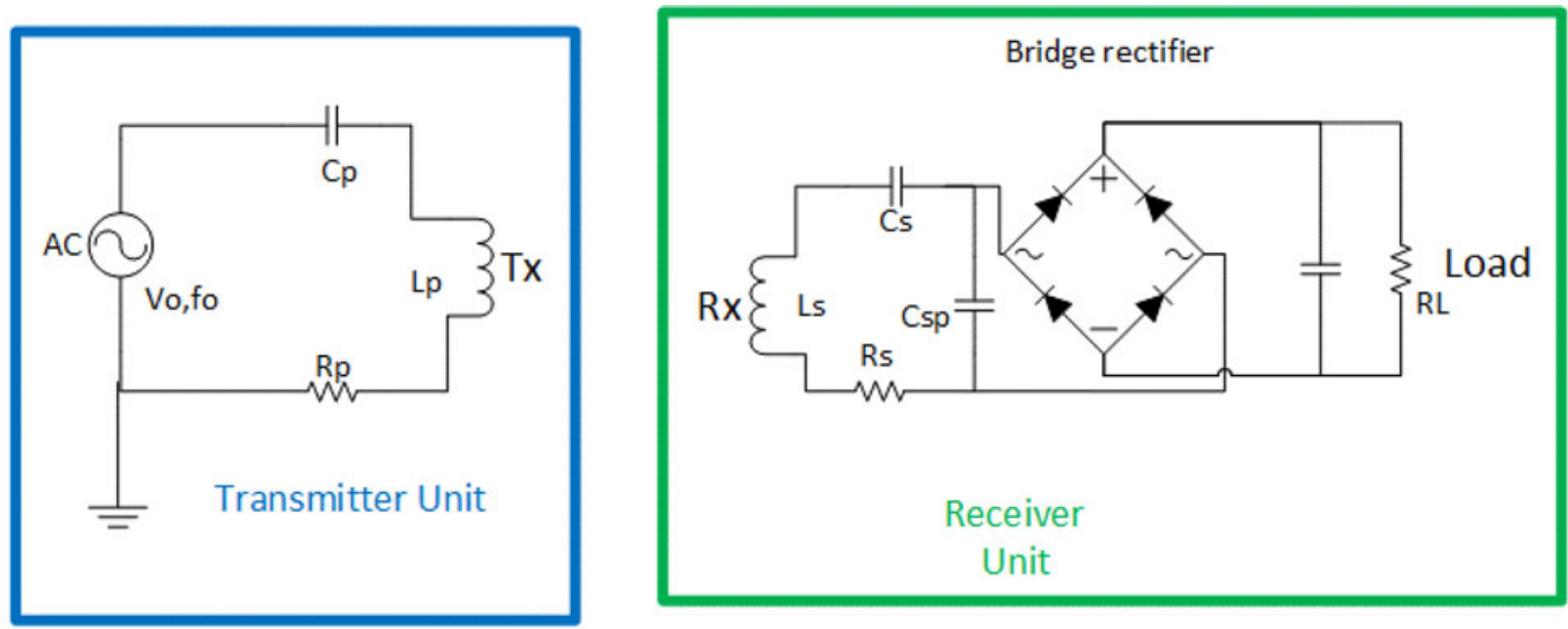

(a)

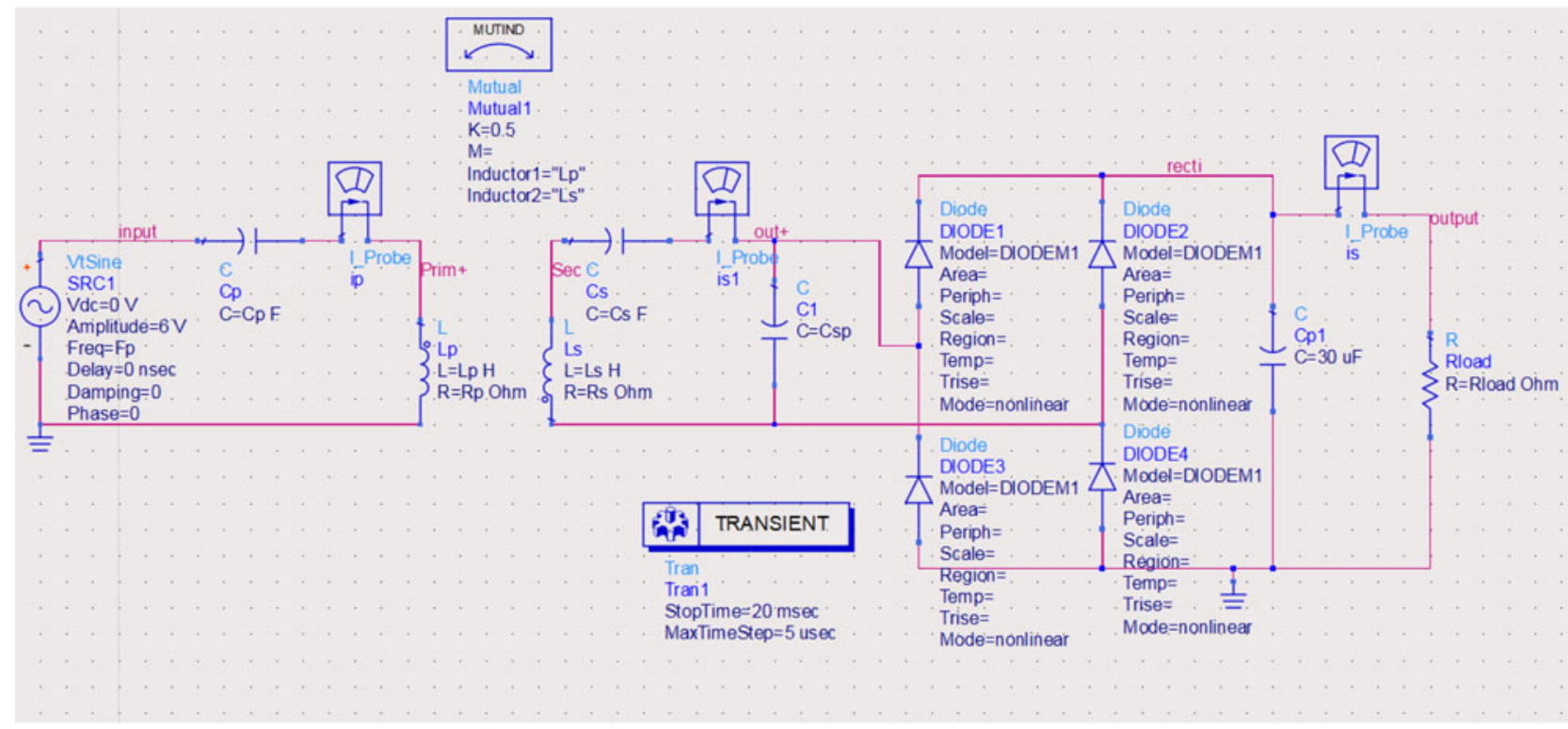

(b)

Fig.5. (a) Circuitry of the receiver and single coil transmitter units. (b) ADS simulation model illustrating receiver circuit and the single coil transmitter.

shows the output efficiency of the system when charging the battery for increasing resistance as SOC increases towards full charge at $200 \Omega$. At a low charge, the system has higher and over time the efficiency drops as the battery continues to charge.

\section{D) Misalignment calculations}

Simulations for different alignment conditions were done in MATLAB using equation (22) from [71]. The translational misalignment, $d_{t m}$ was simulated at a varying distance of separation, $d_{r}$ between the coils as shown in Fig. 7 .

Figure 8 shows the plotted power efficiency against a changing transition misalignment, $d_{t m}$ going from o to $7 \mathrm{~cm}$ at a varying distance of separation, $d_{r}$, ranging from o to $4 \mathrm{~cm}$. The simulations suggest high coupling at smaller $d_{t m}$ and $d_{r}$ distances and tend to zero as the coils are further separated as a result of a lowered coupling factor. The analysis suggests that a misalignment up to about $3 \mathrm{~cm}$ will not affect the performance of the proposed system (since PTE is well above $10 \%$ ) as this is usually the normal sitting position of the user.

\section{EXPERIMENTAL PRDCEDURE}

The amount of power transferred with the system varied depending on the load resistance connected to the receiver. Moreover, a range of dummy loads was tested to understand the battery's impedance since the battery's charging and discharging activity is a chemical process.

\section{A) WPT efficiency}

The first test procedure is to carry out measurements to determine the power efficiency of the WPT system. The connection was done between the wireless power system consisting of a 


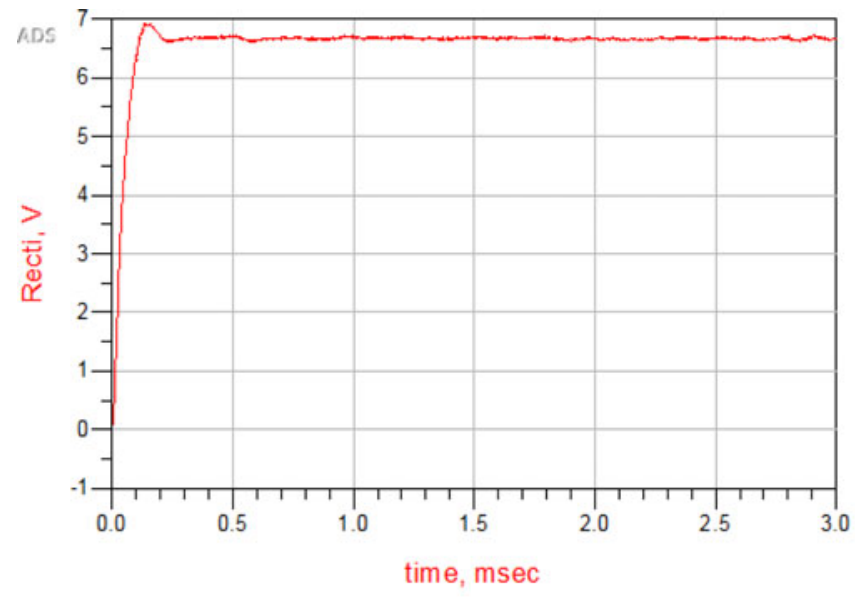

(a)

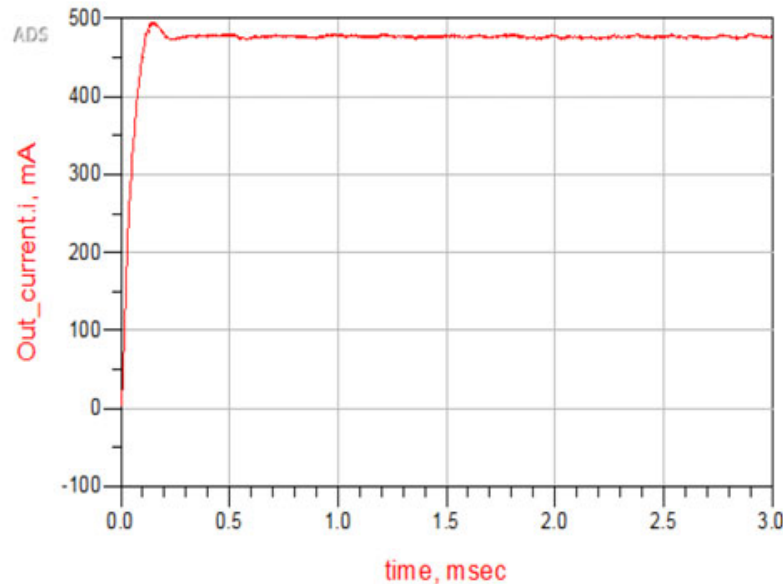

(b)

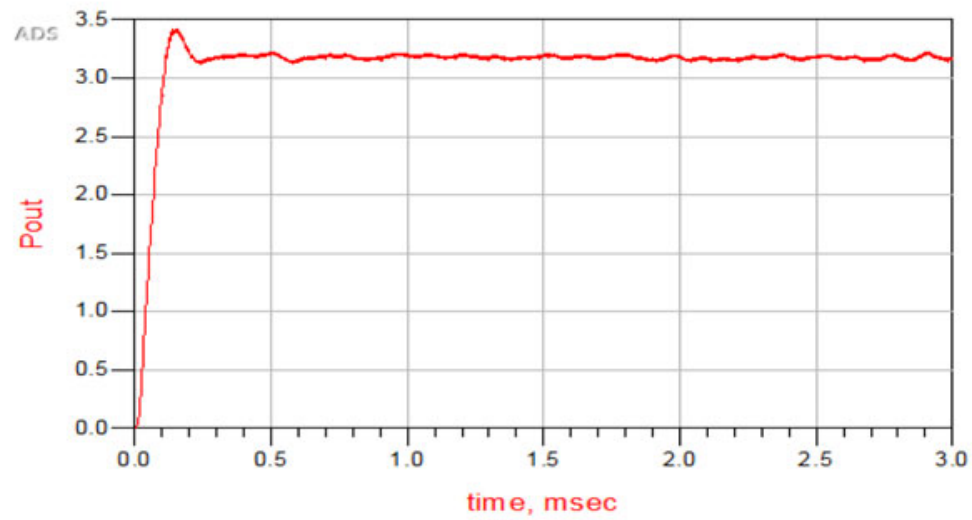

(c)

Fig. 6. ADS simulation results at $15 \Omega$ : (a) voltage, (b) current, and (c) power.

dummy load, a receiver and transmitter. The methods, steps, and relevant documentation are described in [66]. These steps serve as a precaution against wrong connections which could lead to components blowing up.

\section{B) Three-Element Array}

The next step was to replace the single coil with an array of three overlapping coils; i.e. a $3 \times 1$ array. The coils overlap each other to achieve uniform distribution of the magnetic field, without fields canceling each other [39]. The 3-coil

Table 4. Output result from simulation.

\begin{tabular}{llllll}
\hline Load $(\boldsymbol{\Omega})$ & $\begin{array}{c}\text { Output } \\
\text { voltage } \\
(\mathbf{V})\end{array}$ & $\begin{array}{c}\text { Output } \\
\text { current } \\
(\mathbf{A})\end{array}$ & $\begin{array}{c}\text { Power } \\
\text { out } \\
(\mathbf{W})\end{array}$ & $\begin{array}{c}\text { Power } \\
\text { in (W) }\end{array}$ & Efficiency (\%) \\
\hline 5 & 6.54 & 1.34 & 8.7636 & 11 & 79.7 \\
7 & 6.63 & 0.91 & 6.0333 & 7.7 & 78.4 \\
10 & 6.69 & 0.6 & 4.014 & 5.2 & 77.2 \\
15 & 6.8 & 0.47 & 3.19 & 4.2 & 77 \\
20 & 7.11 & 0.35 & 2.53 & 3.5 & 72.4 \\
25 & 7.31 & 0.29 & 2.14 & 3 & 71 \\
50 & 7.64 & 0.15 & 1.169 & 1.92 & 61 \\
75 & 7.64 & 0.10 & 0.78 & 1.65 & 47 \\
100 & 7.72 & 0.07 & 0.59 & 1.44 & 41 \\
200 & 7.77 & 0.03 & 0.30 & 1.32 & 22 \\
\hline
\end{tabular}

array is the 760308106 wireless charging coil from Wurth Electronic made of ferrite core material. The middle coil has an inductance of 11.5 and $12.5 \mu \mathrm{H}$ for the side coils. The coils were connected in parallel to the transmitter and tested with the receiver without the battery, as described in Fig. 9.

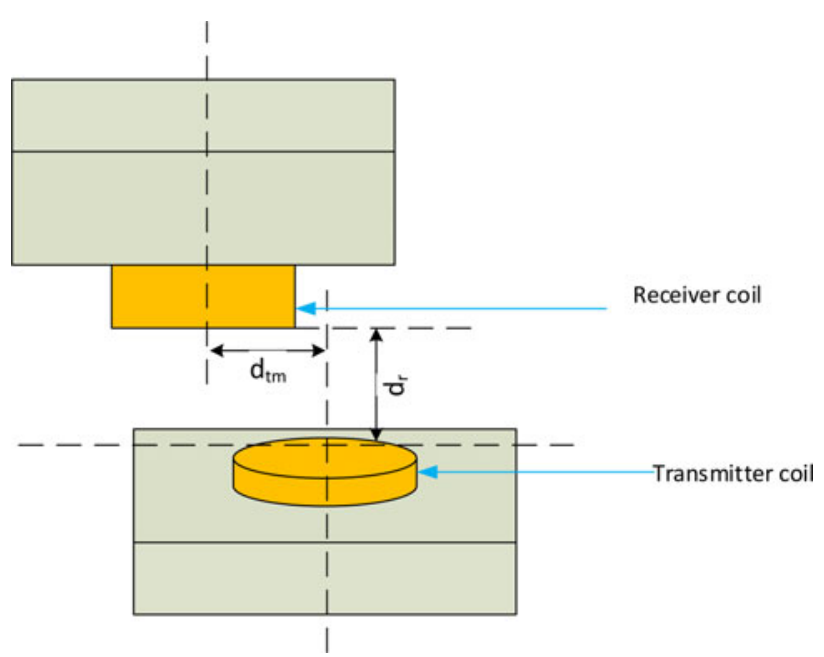

Fig. 7. Basic configuration of translational misalignment between the coils. 


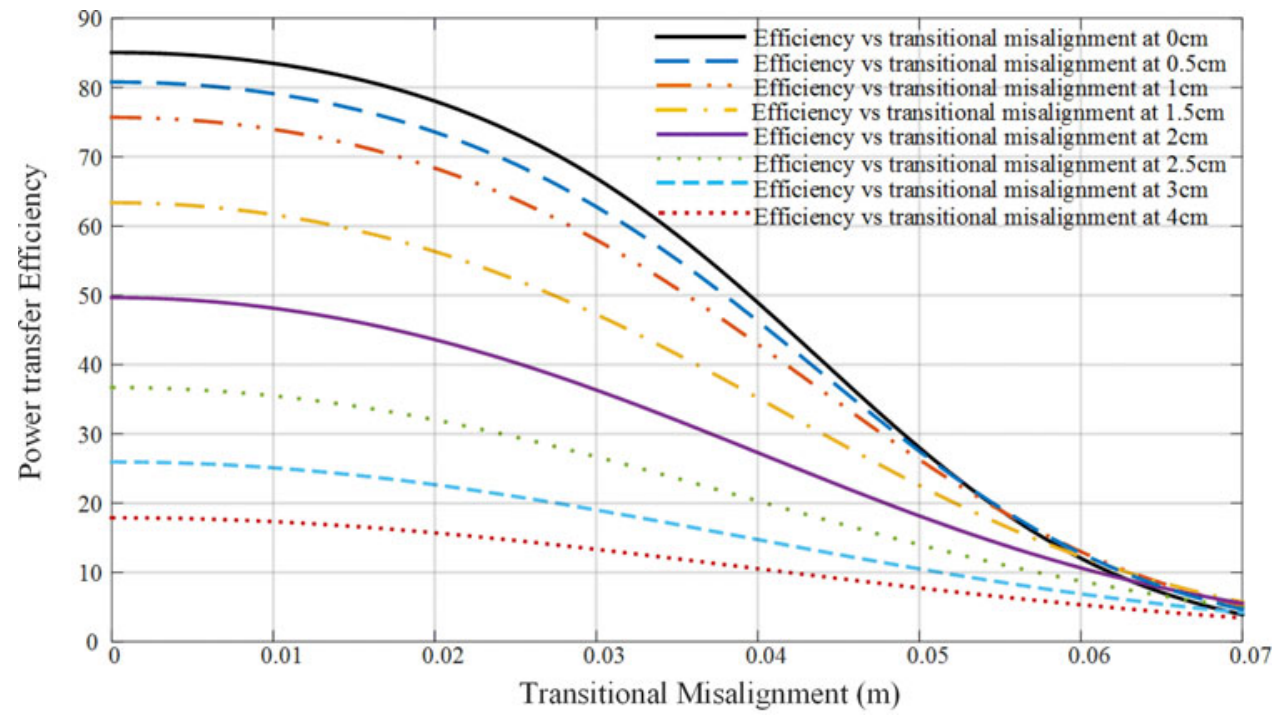

Fig. 8. Power transfer efficiency at different misalignment positions shown in Fig. 7 by varying the distance between the transmitter and receiver coils in $x$ and $y$ directions.

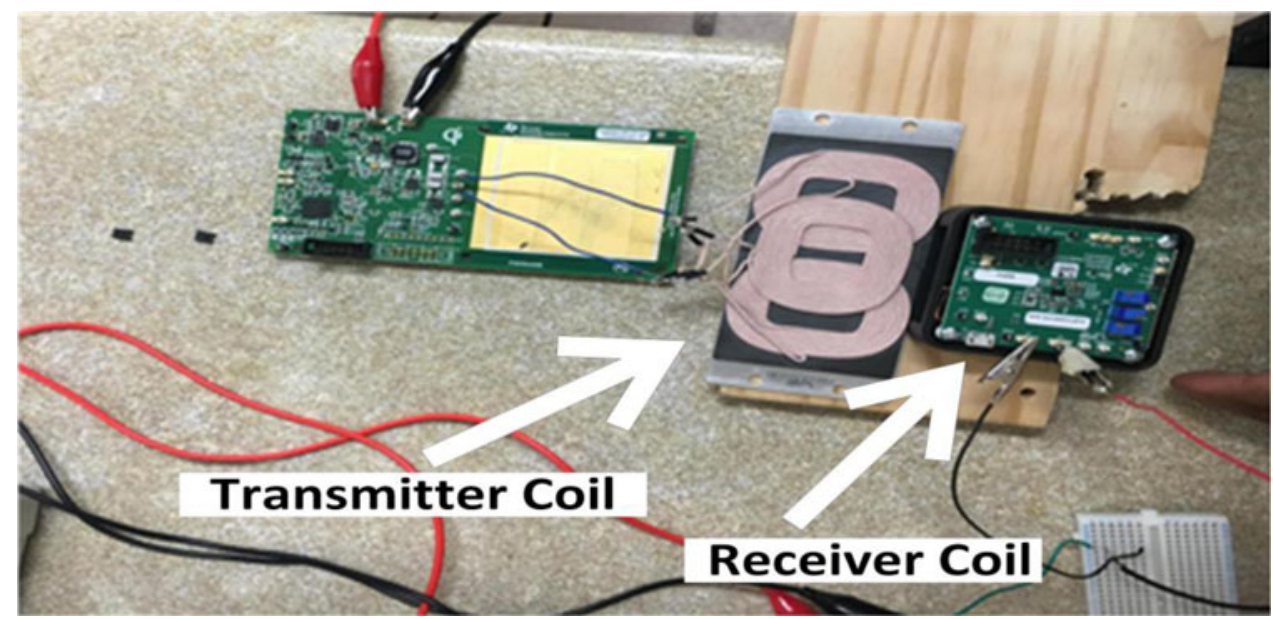

Fig. 9. Single transmitter coil replaced by the $3 \times 1$ array.

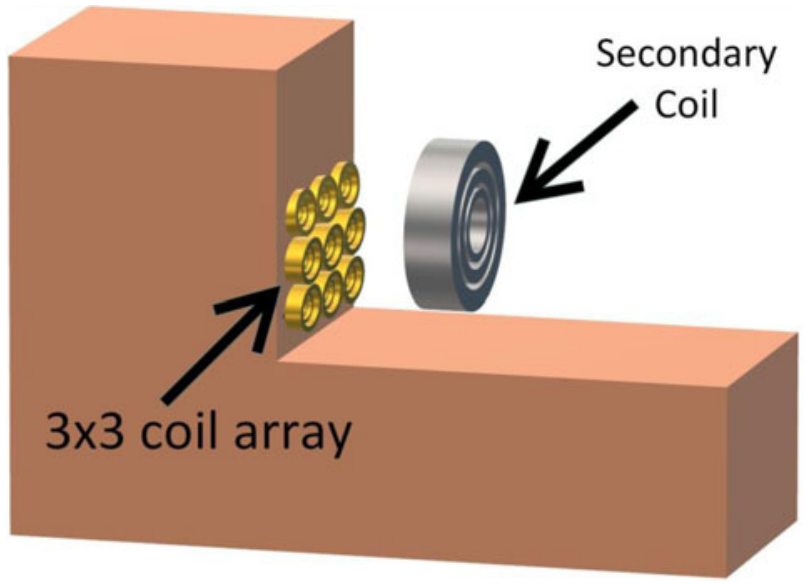

Fig. 10. Model illustrating the primary coil arrangement in the backrest.

\section{C) $3 \times 3$ Coil array}

In this set-up a couple of rows were added to the $3 \times 1$ array (as described above) to increase the free positioning range on the backrest. Only the primary coils next to the receiver activated the power transfer process. This coil arrangement was made of three single $3 \times 1$ coil array resulting in a $3 \times 3$ coil arrangement array as described in Fig. 10.

\section{EXPERIMENTAL RESULTS}

\section{A) WPT efficiency measurement}

The wireless PTE of the system was calculated by measuring the input power at the transmitter and the output power at the receiver as expressed by: $\eta=P_{R X} / P_{T X} 100 \%$, where $\eta$ is the efficiency, $P_{R X}$ is the output power in watts and $P_{T X}$ 


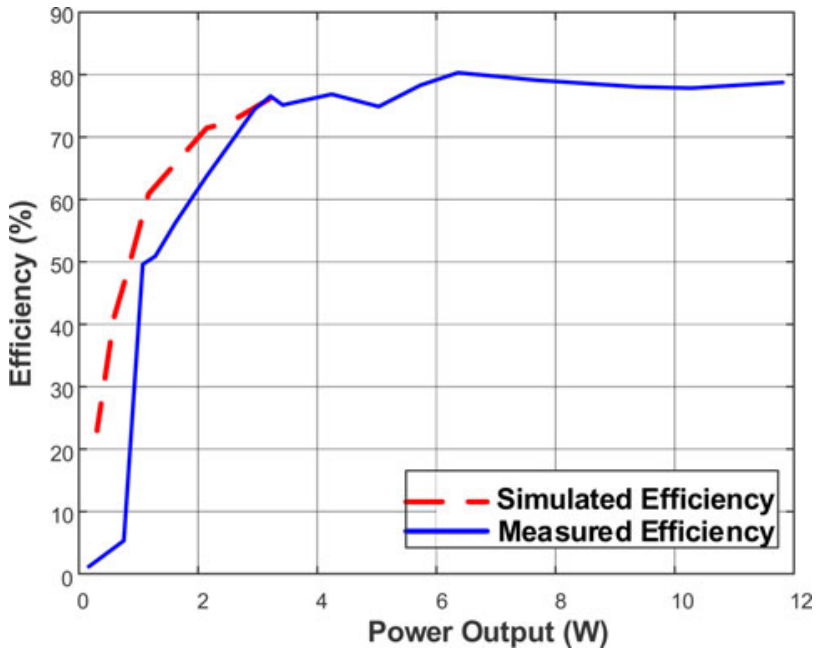

Fig. 11. Measured and simulated efficiency.

is the input power in watts. The efficiency of the system went up to $80 \%$ and decreased as the load resistance increased.

Figure 11 shows the efficiency plot of the simulated and measured device. From this plot we are certain the WPT system works properly.

\section{B) Power measurement}

An open circuit test was done to estimate the batteries SOC, which is the maximum possible charge inside a battery at

Table 5. Open-circuit measurement using industrial charger.

\begin{tabular}{lllll}
\hline $\begin{array}{l}\text { Charger } \\
\text { voltage (V) }\end{array}$ & $\begin{array}{c}\text { Charger } \\
\text { current (A) }\end{array}$ & $\begin{array}{l}\text { Time } \\
(\text { hrs })\end{array}$ & $\begin{array}{l}\text { Voltage per } \\
\text { Cell (V/cell) }\end{array}$ & $\begin{array}{c}\text { Estimated } \\
\text { saturation } \\
\text { capacity (\%) }\end{array}$ \\
\hline 8.79 & 0.63 & 0.5 & 0 & 0 \\
8.79 & 0.63 & 1 & 2.9 & 69 \\
8.79 & 0.63 & 1.5 & 3.4 & 80.9 \\
8.79 & 0.63 & 2 & 3.51 & 83.5 \\
8.79 & 0.63 & 2.5 & 3.57 & 85 \\
9.56 & 0.38 & 3 & 3.9 & 92 \\
\hline
\end{tabular}

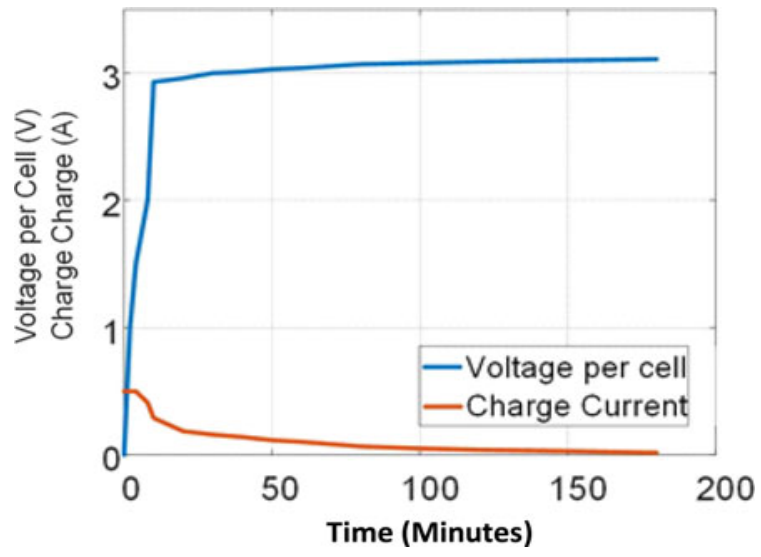

Fig. 13. Voltage-current curve of wireless power system and battery pack.

Table 6. Discharge result of battery.

\begin{tabular}{|c|c|c|c|c|c|}
\hline \multicolumn{3}{|c|}{ Industrial charger } & \multicolumn{3}{|c|}{ WPT system } \\
\hline $\begin{array}{l}\text { Time } \\
\text { (hrs) }\end{array}$ & $\begin{array}{c}\text { Voltage } \\
\text { (V) }\end{array}$ & $\begin{array}{c}\text { Current } \\
\text { (A) }\end{array}$ & $\begin{array}{l}\text { Time } \\
\text { (hrs) }\end{array}$ & $\begin{array}{c}\text { Voltage } \\
\text { (V) }\end{array}$ & $\begin{array}{c}\text { Current } \\
\text { (A) }\end{array}$ \\
\hline 0 & 7.49 & 0.64 & 0 & 7 & 0.46 \\
\hline 0.5 & 7.4 & 0.626 & 1 & 6.8 & 0.43 \\
\hline 1 & 7.04 & 0.61 & 2 & 6.08 & 0.42 \\
\hline 2 & 6.8 & 0.58 & 2.5 & 5.8 & 0.39 \\
\hline 3 & 6.3 & 0.56 & & & \\
\hline 4 & 6.2 & 0.53 & & & \\
\hline 5 & 5.9 & 0.5 & & & \\
\hline
\end{tabular}

any one time. It mainly involves measuring the two terminals of a battery in open-circuit as described in [72] to obtain the voltage per cell. The battery was charged using an industrial charger and results from this were compared to the charging process done by the wireless power system, shown in Table 5, Fig. 12.

When the battery starts to charge, the voltage starts to rise quickly while the current is constant and then when charging progresses towards saturation, the current starts to drop while the voltage remains constant until terminated at stage 3 . Meanwhile the charge capacity increases as shown in Fig. 13.

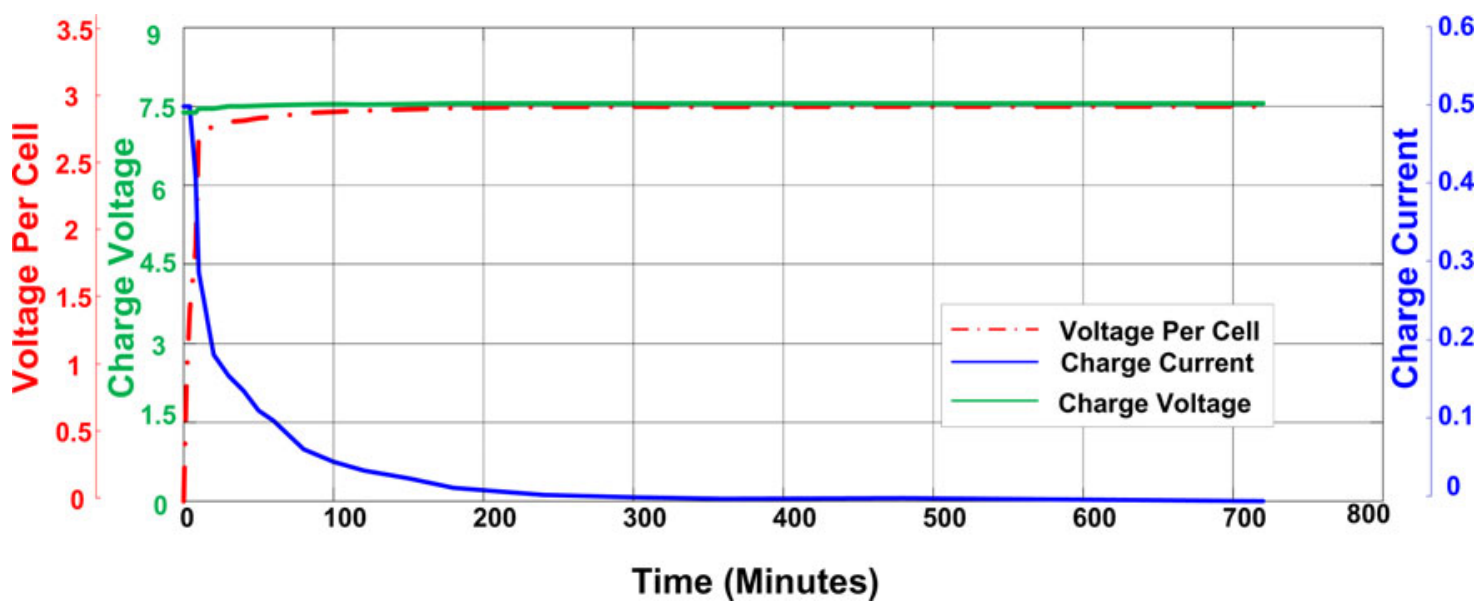

Fig. 12. Open-circuit measurements using WPT system. 


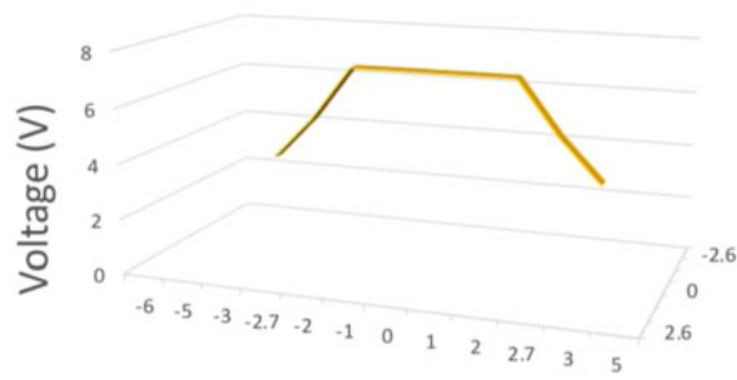

Length $(\mathrm{cm})$

(a)

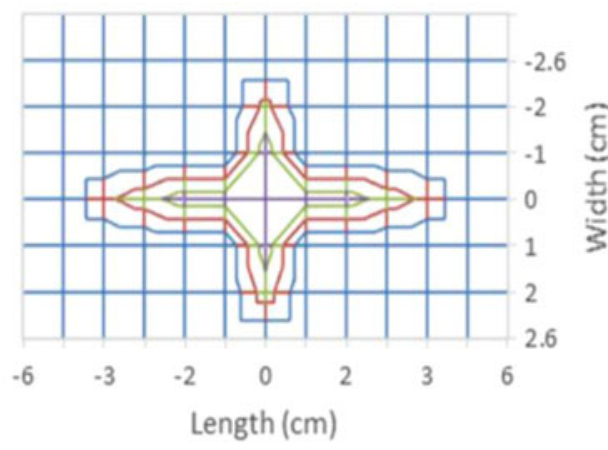

(b)

Fig. 14. Measured induced voltage in the secondary coil for the $3 \times 1$ array. (a) $3 \mathrm{D}$ representation, (b) contour plot representation.

Table 7. Alignment results.

\begin{tabular}{|c|c|c|c|c|}
\hline & \multicolumn{2}{|c|}{ Single coil } & \multicolumn{2}{|c|}{ 3-Coil Array } \\
\hline Model & \multicolumn{2}{|c|}{ 760308141(Wurth Electronic) } & \multicolumn{2}{|c|}{760308106 (Wurth Electronic) } \\
\hline Inductance $(\mu \mathrm{H})$ & \multicolumn{2}{|c|}{10} & \multicolumn{2}{|c|}{$12.5,11.5,12.5$} \\
\hline Resonance frequency $(\mathrm{MHz})$ & \multicolumn{2}{|l|}{11} & \multicolumn{2}{|l|}{14} \\
\hline \multirow[t]{2}{*}{ Operating Area $\left(\mathrm{cm}^{2}\right)$} & \multicolumn{2}{|l|}{1.56} & \multicolumn{2}{|l|}{20} \\
\hline & Displacement $(\mathrm{cm})$ & Voltage (V) & Displacement $(\mathrm{cm})$ & Voltage (V) \\
\hline Ideal Position & 0 & 7.05 & o & 7.08 \\
\hline$X$-axis & 2.4 & 7.01 & 10.6 & 6.96 \\
\hline$Y$-axis & 2.6 & 7.02 & 2.7 & 5.1 \\
\hline$Z$-axis & 2.2 & 6.99 & 3 & 4.96 \\
\hline
\end{tabular}

\section{C) Discharge testing}

It was observed the custom-made battery pack was able to regulate the current going into it. This safety feature was necessary as the battery was used to power a wearable and textile-based commercial product. This led to the significant drop of charge current as compared to the charger which employs a voltage regulator circuitry.

The WPT system cannot raise the voltage per cell higher as the charge current becomes too low resulting in lower saturation which can led to a lower discharge time of $2.5 \mathrm{~h}$ compared to $5 \mathrm{~h}$ seen when the battery reaches a higher capacity

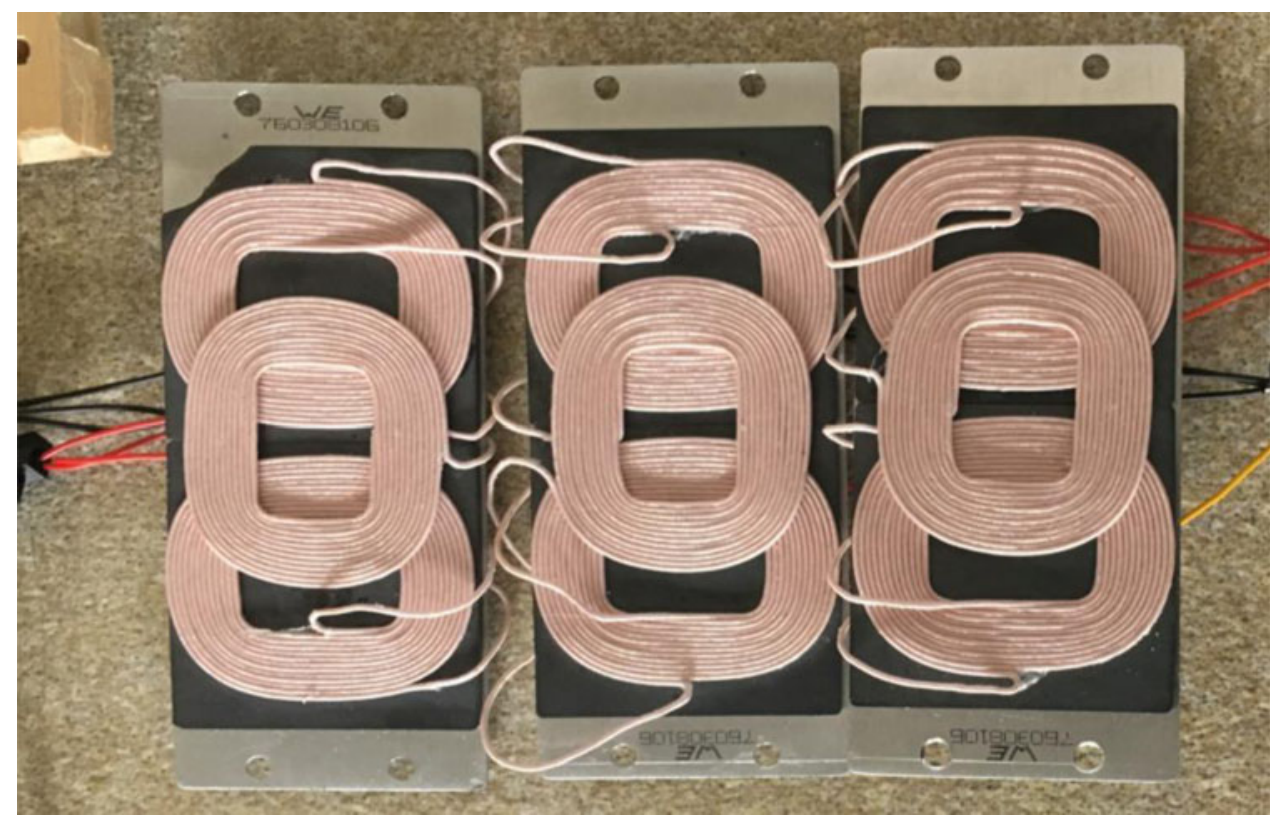

Fig. 15. The $3 \times 3$ coil array structure. 


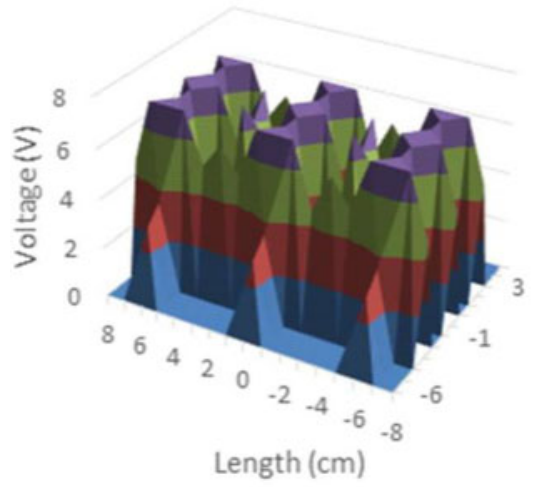

(a)

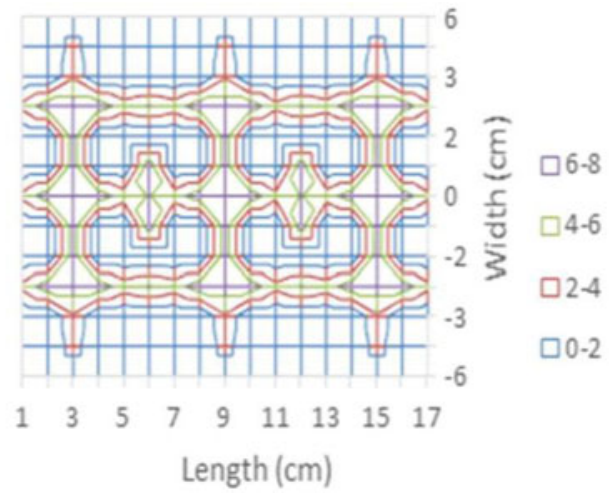

(b)

Fig. 16. Measured induced voltage in the secondary coil for the $3 \times 3$ array. (a) $3 \mathrm{D}$ representation, (b) contour plot. These plots indicate the considerably larger area for the WPT coverage when the $3 \times 3$ array of coils is used.

from the use of an industrial charger. Table 6 shows the voltage discharged after 3 hours when charged with the original charger and WPT system.

\section{D) Alignment testing}

One of the main issues of concern is the systems flexibility particularly relating to alignment. Coupling should occur at any part of the system regardless of the sitting position. A possible solution is the use of an array of coils at the transmitter. The single transmitter coil was replaced by a 3-coil array as shown in Fig. 14, Table 7.

\section{VII. $3 \times 3$ COIL ARRAY IMPLEMENTATIDN}

The voltage induced at the secondary coil using a $3 \times 3$ primary coil array was compared to that of a primary $3 \times 1$ coil array as shown in Figs 14 and 16, this was done to determine the dependence of the flux linkage. The primary coil array was connected in such a way to have an approximate inductance value of $10 \mathrm{uH}$ as specified in [66]. The inner diameter and outer diameter of a single coil element within the array was 44.8 and $15.5 \mathrm{~mm}$, respectively. It has 13 turns and a wire diameter of $1.19 \mathrm{~mm}$. The gap between coils within the array was $1.85 \mathrm{~mm}$ and a single $3 \times 1$ array ( 3 elements) has a dimension of $94.7 \mathrm{~mm} \times 53.35 \mathrm{~mm}$ while the complete $3 \times 3$ array (9 elements) is $94.7 \mathrm{~mm} \times 162 \mathrm{~mm}$.

The $3 \times 3$ array was found to have an increased coverage area of $187 \mathrm{~cm}^{2}$ from that of $28.62 \mathrm{~cm}^{2}$. Figure 14 (b) shows the coverage area as a function of voltage recorded for the $3 \times 1$ array, the concentration, and charge area is seen to have increased in Fig. 16(b). The induced voltage at the receiver was measured by moving the coil center at grid intervals of $17 \mathrm{~cm} \times 11 \mathrm{~cm}$ and spaced at $1 \mathrm{~cm}$ apart. A similar technique was used in [73]. Fig. 15 shows the coil arrangement under the charge area.

High and low peaks for the induced voltage can be observed in Fig. 16. The presence of low peaks indicates a low charge area due to the fact that the coil array elements do not completely overlap each other or are not completely close enough to ensure uniform coverage. Thus, improvements in the transfer efficiency could be possible by using a more compact array.

\section{CONCLUSION AND FUTURE WORK}

A WPT system was designed for a novel wearable heating system that provides warmth to its user. The wireless system consists of an array of coils at the transmitter and a single coil receiver that powers polymer resistors that generate heat when driven by applied current. This provides comfort and heat therapy for the wearer of the belt. The flux distribution was also investigated among two array configurations by moving the receiver across the array surfaces and recording the induced voltage. This helped determine the alignment conditions of the set of the arrays to achieve a considerable area of operation. Results in the paper demonstrated that a significantly increased charge area was made possible by the employed $3 \times 3$ coil array. Further improvements for the system can be made by designing an accompanying voltage regulator integrated circuit such as $\mathrm{LM}_{317}$ (variable regulator) or any fixed regulator such as $\mathrm{LM}_{7} 808$ or $\mathrm{LM}_{7812}$ for better output voltage stability.

\section{ACKNDWLEDGEMENT}

This work was supported in part by the Horizon 2020 European Project CSA-EU (709372) and Scottish Enterprise. The authors would like to indicate that the work is only the authors views and that $\mathrm{H}_{2} \mathrm{O} 2 \mathrm{O}$ is not responsible for any information contained in the paper. The authors would also like to acknowledge the financial support of the UK Engineering \& Physical Sciences Research Council (EPSRC) through the programme grant entitled Sonopill (EP/Ko34537/2). This work was partially supported by the H2020-MSCA-IF-2018 grant \#840854 ViSionRF.

\section{REFERENCES}

[1] Florez-Revuelta, F.; Chaaraoui, A.A.: Active and Assisted Living: Technologies and Applications. Healthcare Technologies, Institution of Engineering and Technology, 2016.

[2] OECD, Pensions at a Glance 2015. OECD and G20 Indicators. OECD Publishing, Paris, 2015. https://doi.org/10.1787/pension glance-2015-en 
[3] McCall, N.: Who Will Pay for Long Term Care? Insights From the Partnership Programs. Health Administration Press, Illinois, 2001.

[4] AAL Association: Objectives -Active and Assisted Living Joint Programme. http://www.aal-europe.eu/about/objectives, (Accessed in January 2019)

[5] Andrew McWilliams BCC Research. CTechnologies for Long-Term Care and Home Healthcare: Global Markets. Code - HLCo79C, 2015

[6] Law, M.; Cooper, B.; Strong, S.; Stewart, D.; Rigby, P.; Letts, L.: The person-environment-occupation model: A transactive approach to occupational performance. Can. J. Occup. Ther., 63 (1) (1996), 9-23.

[7] Baldewijns, G.; et al.: Fall prevention and detection. In active and assisted living: Technologies and applications. IET; Herts, UK, 2016, 203-224.

[8] Vieira, A; et al.: Software for human gait analysis and classification. Bioengineering (ENBENG), 2015 IEEE 4th Portuguese Meeting on, 1,2015

[9] Hempel, R.; Stahl, C.; Stockinger, B.; Kemeth, F.; Vaupel, T.: Outdoor mobility assistance - technologies helping on the way. Institution of Engineering and Technology: Active and Assisted Living: Technologies and Applications. Stevenage: IET, 2016 (Healthcare Technologies 02).

[10] Gorgonio, J.C.; Bou, J.P.; Marín1, F.A.: Location and orientation technologies based on Wi-Fi systems for people with disabilities in indoor environment. IET; Herts, UK, 2016, 261-277.

[11] Longo, D.L.; Kasper, D.L.; Jameson, J.L.; Fauci, A.S.; Hauser, S.L.; Loscalzo, J.: Clinical Problems of Aging: Introduction. McGraw-Hill, New York, USA, 2012

[12] Taub, D.M.; Leeb, S.B.; Lupton, E.C.; Hinman, R.T.; Zeisel, J.; Blackler, S: The escort system: A safety monitor for people living with alzheimer's disease. IEEE Pervasive Comput., 10 (2) (2011), 68-77.

[13] Imhoff, M.; Kuhls, S.: Alarm algorithms in critical care monitoring. Int. Anesthesia Res. Soc., 102 (5) (2006), 1525-1537.

[14] Baig, M.M.; GholamHosseini, H.: A remote monitoring system with early diagnosis of hypertension and hypotension. Point-of-Care Healthcare Technologies (PHT), 2013 IEEE, 2013.

[15] Baig, M.M.; Gholamhosseini, H.; Connolly, M.J.: A comprehensive survey of wearable and wireless ECG monitoring systems for older adults. Med. Biol. Eng. Comput., 51 (5) (2013), 485-495.

[16] Long, Y.; Joonsung, B.; Seulki, L.; Taehwan, R.; Kiseok, S.; Hoi-Jun, Y.: A $3.9 \mathrm{~mW}$ 25-electrode reconfigured sensor for wearable cardiac monitoring system. IEEE J. Solid-State Circuits., 46 (1) (2011), 353-364.

[17] Yoo, J.; Long, Y.; Seulki, L.; Yongsang, K.; Hoi-Jun, Y.: A 5.2 mW self-configured wearable body sensor network controller and a $12 \mu \mathrm{W}$ wirelessly powered sensor for a continuous health monitoring system. IEEE J. Solid-State Circuits., 45 (1) (2010), 178-188.

[18] Xue, R.; Cheng, K.; Je, M.: High-Efficiency wireless power transfer for biomedical implants by optimal resonant load transformation. IEEE Trans. Circuits Syst. I: Regular Papers, 60 (4) (2013), 867-874.

[19] Palazzi, V. et al.: A novel ultra-lightweight multiband rectenna on paper for RF energy harvesting in the next generation LTE bands. IEEE Trans. Microw. Theory Tech. (USA), 66 (1) (2018), 366-379.

[20] Costanzo, A.; et al.: Electromagnetic energy harvesting and wireless power transmission: A unified approach. Proc. IEEE (USA), 102 (2014), 1692-1711. 10.1109/JPROC.2014.2355261.

[21] Panatik, K.Z. et al.: Energy harvesting in wireless sensor networks: A survey. 2016 IEEE 3 rd Int. Symp. on Telecommunication Technologies (ISTT), Kuala Lumpur, 2016, 53-58.
[22] Jeremiah, C.; Chukwuemeka, A.: Wireless power transmission: As an emerging technology. 2017 Int. Conf. on Communication, Control, Computing and Electronics Engineering (ICCCCEE), Khartoum, 2017, 1-6.

[23] Javadi, S.; Mohamedi, A.: A General Review of different methods for Wireless Power Transmission. 2013 ICWN Int. Conf. on Wireless Networks, 1-6.

[24] Singh, S.K.; Hasarmani, T.S.; Holmukhe, R.M.: Wireless transmission of electrical power overview of recent research \& development. Intl' J Comp \& Elec Eng., 4 (2) (2012), 207-210.

[25] Ahire, D.B.; Gond, V.J.: Wireless power transfer system for biomedical application: A review. 2017 Int. Conf. on Trends in Electronics and Informatics (ICEI), Tirunelveli, 2017, 135-140.

[26] Guo, Y. et al.: A load-independent magnetically resonant wireless power transfer system. 2017 Int. Applied Computational Electromagnetics Society Symp. (ACES), Suzhou, 2017, 1-2.

[27] Heacock, D.K.; Fundaro, P.A.: Low-cost battery managementwidening the use of sophisticated battery management in inexpensive products. Thirteenth Annual Battery Conf. on Applications and Advances. Proc. of the Conf., Long Beach, CA, USA, 1998, 247-249.

[28] Xu, D.; Wang, L.; Yang, J.: Research on Li-ion Battery Management System. 2010 Int. Conf. on Electrical and Control Engineering, Wuhan, 2010, 4106-4109.

[29] Zhang, A.; Song, S.; Wang, C.; Zhang, J.; Wang, K.; Li, L.: Research of battery management system for integrated power supply. 2017 Chinese Automation Congress (CAC), Jinan, 2017, 3178-3181.

[30] Wang, B.; Nishino, T.; Teo, K.H.: Wireless power transmission efficiency enhancement with metamaterials. 2010 IEEE Int. Conf. on Wireless Information Technology and Systems, Honolulu, HI, 2010, 1-4.

[31] Costanzo, A.; Masotti, D.: Wirelessly powering: An enabling technology for zero-power sensors, IoT and $\mathrm{D}_{2} \mathrm{D}$ communication. 2015 IEEE MTT-S Int. Microwave Symp., Phoenix, AZ, 2015, 1-4.

[32] Department of Health and Human Services, Food and Drug Administration (FDA). Technical Electronic Product Radiation Safety Standards Committee Meeting, October 25, 2016. FDA-2016-N-0001

[33] Sage, C.; Carpenter, D.: Public health implications of wireless technologies. Pathophysiology: the Official J. Int. Soc. for Pathophysiology/ISP. 16 (2009), 233-246.

[34] Federal Communication Commission (FCC): Wireless Devices and Health Concerns. Consumer Guide, August 2018.

[35] Kalialakis, C.; Georgiadis, A.: The regulatory framework for wireless power transfer systems. Wireless Power Transfer, 1 (2) (2014), 108118.

[36] Bululukova, D.; Kramer, M.: Application of existing wireless power transfer standards in automotive applications. 2014 Int. Conf. on Connected Vehicles and Expo (ICCVE), Vienna, 2014, 863-864.

[37] International Commission on Non-Ionizing Radiation Protection: Icnirp guidelines: for limiting exposure to time-varying electric, magnetic and electromagnetic fields (up to $300 \mathrm{Ghz}$ ). Published in: Health Phys. 74 (4) (1998), 494-522.

[38] Lu, X.; Wang, P.; Niyato, D.; Kim, D.; Han, Z.: Wireless charging technologies: fundamentals, standards, and network applications. IEEE Commun. Surv. Tutorials, 18 (2) (2016), 1413-1426.

[39] van Wageningen, D.; Staring, T.: The Qi wireless power standard. Proc. 14th Int. Power Electronics and Motion Control Conf. (EPE/ PEMC), 2010 
[40] Hui, S.Y.: Planar wireless charging technology for portable electronic products and Qi. Proc. of the IEEE 101(6), 1290-1301, 2013.

[41] Alliance for Wireless Power A4WP Wireless Power Transfer System. in Baseline System Specification (BSS) A4WP-S-0oo1 v1.2, Fremont, CA:Rezence, Alliance for Wireless Power, 2014.

[42] Mehdipour, A.; Moarref, B.; Kia, A.S.; Yazdanipour, M.: Evaluation of inductive coupling and RF-DC for Wireless Power Transmission. 2012 Ninth Int. Conf. on Wireless and Optical Communications Networks (WOCN), Indore, 2012, 1-5.

[43] Amar, A.B.; Kouki, A.B.; Cao, H.: Power approaches for implantable medical devices. Sensors, 15 (2015), 28889-28914.

[44] Zhu, D.; Grabham, N.J.; Clare, L.; Stark, B.H.; Beeby, S.P.: Inductive power transfer in e-textile applications: Reducing the effects of coil misalignment. 2015 IEEE Wireless Power Transfer Conf. (WPTC), Boulder, CO, 2015, 1-4.

[45] Worgan, P.; Pappas, O.; Omirou, T.; Collett, M.: Flexible on-body coils for inductive power transfer to IoT garments and wearables. 2015 IEEE 2nd World Forum on Internet of Things (WF-IoT), Milan, 2015, 297-298.

[46] Grabham, N.J.; Li, Y.; Clare, L.R.; Stark, B.H.; Beeby, S.P.: Fabrication techniques for manufacturing flexible coils on textiles for inductive power transfer. IEEE Sens. J. (USA), 18 (6) (2018), 2599-2606.

[47] RamRakhyani, A.K.; Mirabbasi, S.; Chiao, M.: Design and optimization of resonance-based efficient wireless power delivery systems for biomedical implants. IEEE Trans. Biomed. Circuits and Sys., 5 (1) (2011), 48-63.

[48] Borges Carvalho, N. et al.: Wireless power transmission: R\&D activities within Europe. IEEE Trans. Microw. Theory Tech. (USA), 62 (4) (2014), 1031-1045.

[49] Sardini, E.; Serpelloni, M.: Instrumented wearable belt for wireless health monitoring. Procedia Eng., 5 (2010), 580-583, ISSN 1877-7058.

[50] Catrysse, M.; Puers, R.; Hertleer, C.; Van Langenhove, L.; Van Egmond, H.; Matthys, D.: Towards the integration of textile sensors in a wireless monitoring suit. Sens. Actuators A Phys., 114 (2004), 302-311.

[51] Kurs, A.; Karalis, A.; Moffatt, R.; Joannopoulos, J.D.; Fisher, P.; Soljiacic, M.: Wireless power transfer via strongly coupled magnetic resonances. Science, 317 (2007), 83.

[52] Hatanaka, K.; et al.: Power transmission of a desk with a cord-free power supply. IEEE Trans. Magnetics, 38 (5) (2002), 3329-3331.

[53] Pu, S.; Hui, H.T.: To improve wireless power transmission efficiency by using coil arrays. 2013 IEEE Wireless Power Transfer (WPT), Perugia, 2013, 195-197.

[54] Wu, J.; Wang, B.; Yerazunis, W.S.; Teo, K.H.:Wireless power transfer with artificial magnetic conductors. 2013 IEEE Wireless Power Transfer (WPT), Perugia, 2013, 155-158.

[55] Pacini, A.; Mastri, F.; Trevisan, R.; Masotti, D.; Costanzo, A.: Geometry optimization of sliding inductive links for position-independent wireless power transfer. 2016 IEEE MTT-S Int. Microwave Symp. (IMS), San Francisco, CA, 2016, 1-4.

[56] Kim, J.; Kim, D.; Kim, K.; Park, Y.: Free-positioning wireless charging system for hearing aids using a bowl-shaped transmitting coil. 2014 IEEE Wireless Power Transfer Conf., Jeju, 2014, 60-63.

[57] Jolani, F.; Yu, Y.; Chen, Z.: A planar positioning-free magneticallycoupled resonant wireless power transfer. 2015 IEEE Wireless Power Transfer Conf. (WPTC), Boulder, CO, 2015, 1-3.
[58] Hariri, A.O.; Berzoy, A.; Mohamed, A.A.S.; Mohammed, O.A.: Performance evaluation of a wireless power transfer system using coupled 3D finite element-circuit model. 2015 IEEE Wireless Power Transfer Conf. (WPTC), Boulder, CO, 2015, 1-4.

[59] Shenzhen Lixiang Energy Co., Ltd: Smart Li-Ion Battery Pack Specification. LX-DRFo1H datasheet, Nov. 2017 [Revised Sept. 2011].

[6o] Buchmann, I.: Batteries in A Portable World: A Handbook on Rechargeable Batteries for Non-Engineers, 2nd ed. Cadex Electron. Inc., British Columbia, Canada, 2001.

[61] Johns, B.; Antonacci, T.; Siddabattula, K.: Designing a Qi Compliant Receiver Coil for Wireless Power Systems. Analog Applications Journal, 2012.

[62] Wireless Power Consortium: The Qi Wireless Power Transfer System: Power Class o Specification, Part 1 and 2: Interface Definitions. Version 1.2.3, February 2017 [Online]. Available: http://www.wirelesspowerconsortium.com/downloads/wireless-powerspecification.

[63] Wireless Power Consortium: The Qi Wireless Power Transfer System: Power Class o Specification, Part 4: Reference Designs. pg.165. Version 1.2.3, February 2017 [Online]. Available: http:// www.wirelesspowerconsortium.com/downloads/wireless-powerspecification.

[64] WE-WPCC Wireless Power - 760308141: Würth Elektronik eiSos GmbH \& Co. KG EMC \& Inductive Solutions Max-Eyth-Str. 1 74638 Waldenburg Germany Tel. +49 (o) 7942 945-0.

[65] WE-WPCC Wireless Power Array- 760308106. Würth Elektronik eiSos GmbH \& Co. KG EMC \& Inductive Solutions Max-Eyth-Str. 174638 Waldenburg Germany Tel. +49 (o) 7942 945-0.

[66] BQ500215 bqTESLA Wireless Power Tx EVM Users Guide (SLVUABoA): Ti.com, 2015. [Online]. Available: http://www.ti. com/lit/ug/slvuaboa/slvuaboa.pdf. [Accessed: 03- Aug- 2018].

[67] BQ51025 PWR649 Wireless Power RX EVM Users Guide (SLUUB55): Ti.com, 2014. [Online]. Available: http://www.ti.com/ lit/ug/sluub55/sluub55.pdf [Accessed: 03- Aug- 2018].

[68] Waffenschmidt, E.: Qi Coupling Factor. Wirelesspowerconsortium. com. [Online]. Available: https://www.wirelesspowerconsortium.com/ knowledge-base/magnetic-induction-technology/how-it-works/couplingfactor.html [Accessed: 03- Aug- 2018].

[69] Ohira, T.: Extended k-Q product formulas for capacitive- and inductive-coupling wireless power transfer schemes. IEICE Electron. Express, 11 (9) (2014), 20140147.

[70] Solar, H.; Alonso, M.; Bustamante, P.; Giers, C.: Design of a Wireless Power Transfer receiver with an ad-hoc coil for the Qi Standard. 2015 Conf. on Design of Circuits and Integrated Systems (DCIS), Estoril, 2015, 1-5.

[71] Khan, S.R.; Pavuluri, S.K.; Desmulliez, M.P.Y.: Accurate modeling of coil inductance for near-field wireless power transfer. IEEE Trans. Microw. Theory Tech. (USA), 66 (9) (2018), 4158-4169.

[72] Weng, C.; Sun, J.; Peng, H.: An open-circuit-voltage model of lithium-ion batteries for effective incremental capacity analysis. Proc. of the ASME 2013 Dynamic Systems and Control Conf. DSCC2013, October 21-23, 2013, Palo Alto, CA, USA, 2013.

[73] Achterberg, J.; Lomonova, E.A.; de Boeij, J.: Coil array structures compared for contactless battery charging platform. IEEE Trans. Magn. (USA), 44 (5) (2008), 617-622. 


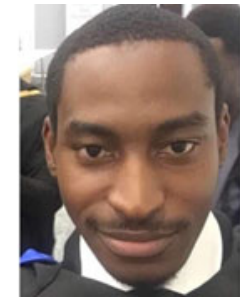

Qassim S. Abdullahi was born in Jeddah, Saudi Arabia. He received MEng with distinction in electrical and electronics engineering from HeriotWatt University, Edinburgh, UK in the summer of 2018 . He is currently pursuing his Ph.D. in electrical engineering. His research area includes compact wearable antennas, frequency selective surface, metamaterials, wearable antennas, and wireless power transfer.

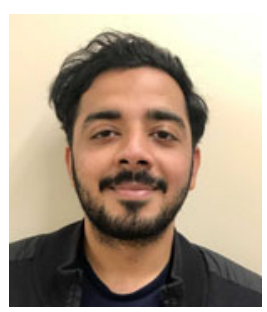

Rahil Joshi was born in Satna, MP, India, and received $\mathrm{BE}$ (Hons) in electronics and communications engineering in 2014 from Birla Institute of Technology and Science, Pilani-Dubai Campus. In 2015, he received MSc in communication and signal processing engineering from Newcastle University, UK. He is currently working towards his Ph.D. in the Institute of Sensors, Signals, and Systems from Heriot-Watt University, UK. His research interests are in areas of compact antennas, planar antennas, wearable antennas, software-defined radio, and wireless power transfer.

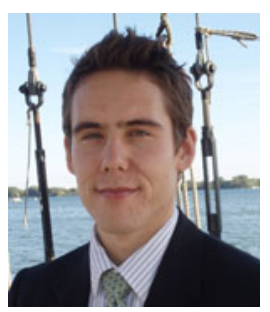

Symon K. Podilchak received BASc in engineering science from the University of Toronto, Ontario, Canada, in 2005. While studying at Queen's University in Kingston, Ontario, Canada he received an MASc and a Ph.D. in electrical engineering in 2008 and 2013, respectively, and he was honored with an Outstanding Dissertation Award for his Ph.D. from the same institution. From 2013 to 2015, Symon was an assistant professor at Queen's University. He then joined Heriot-Watt University, Edinburgh, Scotland, UK in 2015 as an assistant professor and became an associate professor in 2017. Currently his research is supported by a $\mathrm{H} 2020$ Marie Skłodowska-Curie European Research Fellowship and cross-appointed at Edinburgh University, Scotland.

Dr. Podilchak is a registered professional engineer (P.Eng.) and has had industrial experience as a computer programmer, and has designed 24 and $77 \mathrm{GHz}$ automotive radar systems with Samsung and Magna Electronics. Recent industry experience also includes the design of highfrequency surface-wave radar systems, professional software design and implementation for measurements in anechoic chambers for the Canadian Department of National Defence and the SLOWPOKE Nuclear Reactor Facility. Dr. Podilchak has also designed new compact multiple-input-multiple-output (MIMO) antennas for wideband military communications, highly compact circularly polarized antennas for microsatellites with COM DEV International, as well as new wireless power transmission systems for Samsung. His research interests include surface waves, leaky-wave antennas, metasurfaces, UWB antennas, phased arrays, and CMOS integrated circuits.

Dr. Podilchak has been the recipient of many best paper awards and scholarships; most notably Research Fellowships from the IEEE Antennas and Propagation Society, as well as, the IEEE Microwave Theory and Techniques Society. He also received a Postgraduate Fellowship from the Natural Sciences and Engineering Research Council of Canada (NSERC) and four Young Scientist Awards from the International Union of Radio Science (URSI). In 2011 and 2013 he received student paper awards at the IEEE International Symposium on Antennas and Propagation, and in 2012, the best paper prize for Antenna Design at the European Conference on Antennas and Propagation for his work on CubeSat antennas, and in 2016, received The European Microwave Prize for his research on surface waves and leaky-wave antennas. In 2017 and 2019, Dr. Podilchak was bestowed a Visiting Professorship Award at Sapienza University in Rome. In 2014, the IEEE Antennas and Propagation Society recognized Dr. Podilchak as an Outstanding Reviewer for the IEEE Transactions on Antennas and Propagation. Dr. Podilchak was also the founder and first chairman of the IEEE Antennas and Propagation Society and the IEEE Microwave Theory and Techniques Society, Joint Chapter of the IEEE Kingston Section in Canada as well as Scotland. In recognition of these services, the IEEE presented Dr. Podilchak with an Outstanding Volunteer Award in May 2015. Currently he also serves as a lecturer for The European School of Antennas and is an associate editor to the journal IET Electronic Letters.

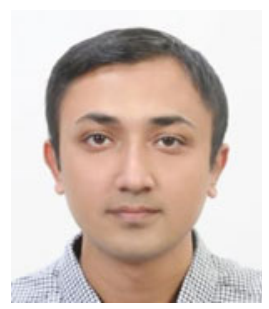

Sadeque Reza Khan received BSc in electronics and telecommunication engineering from the University of Liberal Arts Bangladesh, Dhaka, Bangladesh, in 2010 and an MTech in VLSI design from the National Institute of Technology, Mangalore, Karnataka, India, in 2014. $\mathrm{He}$ is currently pursuing Ph.D. in electrical engineering at Heriot-Watt University, Edinburgh, UK.

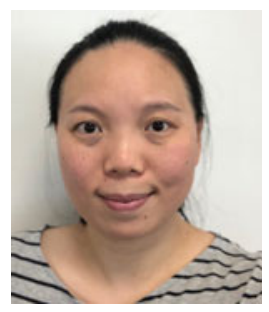

Dr. Meixuan Chen holds a Ph.D. in textiles, awarded by the School of Textiles and Design, Heriot-Watt University in 2017. Her Ph.D. research began with practical experiments in designing interactive textiles and then investigated how this design aesthetics can affect viewers' emotions and personal preferences. Prior to Ph.D. studies, she went on to be trained as a textile designer specializing in knitted textiles, at Central Saint Martin's College of Arts and Design in London, and had completed a Bachelor degree in textiles design and a Master degree in design for Textiles Futures. She has been working as a research associate in School of Textiles and Design at Heriot-Watt University. The main focus of her role is to provide specialist support and conduct research projects in textile design and materials engineering.

Dr. Jean Rooney Bio not available at the time of publication.

Dr. John Rooney Bio not available at the time of publication. 


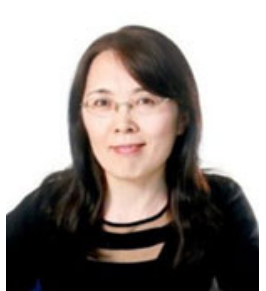

Dr. Danmei Sun is an associate professor and has over 25 years work experience in textile materials and engineering both practical and theoretical. Her research interests include smart polymers and fibres, engineering design $2 \mathrm{D} / 3 \mathrm{D}$ textile structures for technical textiles and performance clothing, thermal regulated textiles and clothing by embedding thermal chemicals, finite element modelling and prediction or textile properties and environmental friendly finishing. Her research has been supported by various funding bodies such as UK Dstl/MoD, Oil and Gas Innovation Centre, Scottish Funding Council, as well as company partners such as Harris Tweed, Iron and Ocean Ltd. etc.

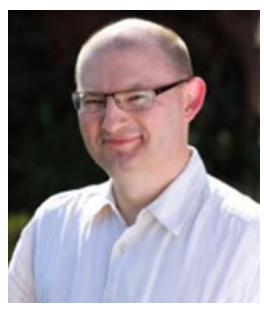

Marc P. Y. Desmulliez (SM'87) received a Ph.D. in optoelectronics from Heriot-Watt University, Edinburgh, $\mathrm{UK}$, in 1995 . He is currently a professor of microsystems engineering with Heriot-Watt University, where he leads the Multimodal Sensing and Micro-Manipulation Research Group.

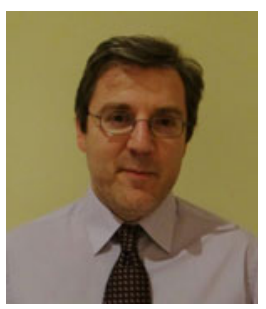

Dr. Apostolos Georgiadis was born in Thessaloniki, Greece. He received BS in physics and an MS in telecommunications from the Aristotle University of Thessaloniki, Greece, in 1993 and 1996, respectively. He received Ph.D. in electrical engineering from the University of Massachusetts, Amherst, in 2002. In 1995, he spent a semester with Radio Antenna Communications (RAC), Milan Italy, working on Yagi antennas for UHF applications. In the summer of 2000, he was with Telaxis Communications, South Deerfield, MA, USA, where he assisted in the design and testing of a pillbox antenna for LMDS applications.. In 2002 he joined Global Communications Devices (GCD), North Andover, MA, USA, as a systems engineer and worked on CMOS transceivers for wireless network applications. In June 2003, he joined Bermai, Inc., Minnetonka, MN, USA, as an RF/Analog Systems Architect. In 2005 he joined the University of Cantabria, Spain, as a Juan de la Cierva Fellow researcher. In 2006 he was a consultant for Bitwave Semiconductor, Lowell, MA, USA. In addition he collaborated with ACORDE S.A., Santander, Spain, in the design of integrated CMOS VCOs for ultra-wideband (UWB) applications. In March 2007 he joined CTTC as a senior research associate in the area of Communications Subsystems. In 2013-2016 he was a group leader of the Microwave Systems and Nanotechnology Department of CTTC. In July 2016 he joined Heriot-Watt University, Edinburgh as an associate professor. In 1996, Dr. Georgiadis received a Fulbright Scholarship for graduate studies at the University of Massachusetts, Amherst. He received the Outstanding Teaching Assistant Award from the University of Massachusetts, Amherst, in 1997 and 1998. He also was the recipient of the Eugene M. Isenberg Award from the Isenberg School of Management, University of Massachusetts, Amherst, in 1999 and
2000. He was the general chair of 2011 IEEE RFID-TA Conference and general co-chair of the 2011 IEEE MTT-S IMWS on Millimeter Wave Integration Technologies. He was the chairman of COST Action ICo803 RF/Microwave communication subsystems for emerging wireless technologies (RFCSET). He is vice-chair of COST Action IC1301 Wireless Power Transmission for Sustainable Electronics (WiPE). He was the coordinator of Marie Curie Industry-Academia Pathways and Partnerships (IAPP) project Symbiotic Wireless Autonomous Powered system (SWAP). He is member of the IEEE MTT-S TC-24 RFID Technologies (past chair) and member of IEEE MTT-S TC-26 Wireless Energy Transfer and Conversion. He serves as an associate editor of the IEEE Journal on RFID. He has been associate editor of the IEEE Microwave and Wireless Components Letters, the IET Microwaves Antennas and Propagation and the IEEE RFID Virtual Journal. He co-founded and was editorin-chief of the Cambridge Wireless Power Transfer Journal. He was a distinguished lecturer of IEEE Council on RFID. He is URSI fellow and chair of URSI Commission D: Electronics and Photonics. He is IEEE senior member. His research interests include energy harvesting and wireless power transmission, RFID technology, active antennas and phased array antennas, inkjet and $3 \mathrm{D}$ printed electronics, millimeter wave systems. He has published more than 200 papers in peer-reviewed journals and international conferences.

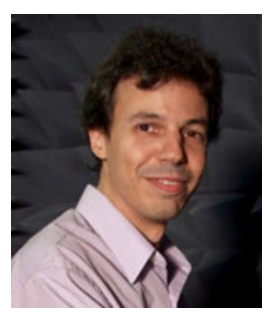

Dr. Dimitris E. Anagnostou (S'98M'05-SM'10) received the BSEE degree from the Democritus University of Thrace, Greece, in 2000, and the MSEE and Ph.D. from the University of New Mexico, Albuquerque, NM, USA, in 2002 and 2005, respectively. From 2005 to 2006, he was a postdoctoral fellow at the Georgia Tech, Atlanta, GA, USA. In 2007, he joined as assistant professor the SD School of Mines \& Technology, SD, USA, where he received promotion as associate professor with tenure. In 2016, Dr. Anagnostou joined the Heriot-Watt University, Institute of Signals, Sensors and Systems (ISSS) where he is currently a MSCA IF fellow and associate professor. Dr. Anagnostou has also worked at the Kirtland AFB, NM, and at the Democritus University of Thrace, Greece.

Dr. Anagnostou has authored or co-authored more than 130 peer-reviewed papers (h-index: 21) and he holds two U.S. patents. His interests include electromagnetic devices (antennas, microwave circuits, reconfigurable RF electronics, RADAR, sensors, and wearable electronics) for space satellites, defense, assisted living, and consumer applications such as $5 \mathrm{G}$, as well as phase-change materials ( $\mathrm{VO}_{2}$ ), artificial neural networks, printable spacecraft, and security printing.

Dr. Anagnostou has received multiple prestigious awards, including the IEEE John D. Kraus Antenna Award, the DARPA Young Faculty Award by the U.S. Department of Defense, the ASEE Campus Star Award by the American Society for Engineering Education, the UNM Young Alumni Award, the SDSMT Honored Faculty Award (4 times), and many others. Most recently, he was awarded the $\mathrm{H}_{2} \mathrm{O} 20$ Marie Skłodowska-Curie European Research Fellowship that currently supports his research. Many of his students have also been recognized with 
IEEE and university awards such as Engineering Prize award (HWU) and Best PhD Thesis award (SDSMT).

Dr. Anagnostou serves or has served as associate editor for the IEEE Transactions on Antennas and Propagation, the IET Microwaves, Antennas and Propagation, IEEE Access, and as guest editor for the IEEE Antennas and Wireless Propagation Letters (two special issues), the Hindawi Intl' Journal of Antennas and Propagation (two special issues), and the MDPI Technologies (one special issue). He is a member of the IEEE-APS Educational Committee, a member of the Technical Program Committee (TPC) and session chair for IEEE-APS and EuCAP Intl' Symposia, and a reviewer for international journals such as Nature and IEEE Transactions. He is a member of Eta Kappa Nu (HKN) Honor Society, ASEE, and a professional engineer (PE) of the Technical Chamber of Greece (TEE). 